\title{
Pure and mixed-oxide thin film model systems grown on sodium chloride templates for structural and catalytic studies
}

\author{
Simon Penner \\ Institute for Physical Chemistry, University of Innsbruck, Innrain 52a, A-6020 Innsbruck
}

Corresponding author: S. Penner, simon.penner@,uibk.ac.at, Tel: 004351250758003

Keywords: Electron Microscopy, architectured oxides, $\mathrm{NaCl}(001)$, phase transformation, epitaxial growth, metal-support interaction, mechanistic studies 


\begin{abstract}
Preparation and application possibilities for thin film model systems of isolated pure oxides and mixed oxide systems are reviewed. Vacuum deposition of oxides on $\mathrm{NaCl}(001)$ growth templates or post-oxidation of initially prepared metal particles almost exclusively led to wellstructured and -defined systems, which are perfect starting systems for in-depth structural, compositional and property characterization. The advantages of the chosen preparation pathways are exemplarily discussed for a number of case studies, showing the full range of application possibilities, including easy and reproducible preparation of oxide nanoarchitectures, studies of detailed monitoring of phase transformations in oxide systems and more complex applications such as the influence of the oxide's properties on intermetallic formation in supported metal/oxide systems or the preparation of mixed oxide model systems with defined morphology and structure. Particular emphasis is placed on how structural characterization (high-resolution transmission electron microscopy, atomic force microscopy), spectroscopic methods (X-ray photoelectron spectroscopy) and kinetic measurements can be successfully combined to result in unambiguous structureactivity/selectivity and property relationships, leading to an in-depth understanding of the participating oxide structures on an atomic and molecular level.
\end{abstract}




\section{Introduction}

Metal oxides are one of the most promising materials at the intersection of the primary research areas in chemistry, physics, and materials science. Potential application areas range from protective coatings over solar cells and sensors to microelectronics and the use as catalysts in a variety of chemical reactions [1,2]. Yet, despite these advantages, the use of oxides does not come without strings attached. The latter are usually connected with the complex chemistry of these materials, which subsequently hampers drawing decisive conclusions, e.g. regarding reaction mechanisms or structure-property relationships [1]. As a representative example, nicely showing the drawbacks of using oxides, is the large research field of catalysis [1]. In this case, oxides are typically either used as supports for other catalytically active, mostly metallic, materials or as catalysts themselves. However, whereas the catalysis of noble metals is already well understood, several factors have to be additionally considered if oxides are used, including: surface vs. bulk structural terminations, the presence of various oxidation states, possible phase transformations between different polymorphic modifications, hydroxylation or other chemical modifications of the oxide surface or the presence of defects in general [1]. All these factors govern the geometric and electronic structure of the oxidic materials, with possible and likely influences on their use. To extend these considerations, mixed oxides gain increased interest especially in sensor technology or (photo-) catalysis [3,4]. As the corresponding pure oxide systems, they might be present as supported systems, combined with a dopant or as bulk mixed-oxide phases [1]. One of the well-known examples of the former are supported vanadium oxide catalysts, which have been scrutinized for catalytic applications over the last three decades [4]. Mixed bulk Mo-V-Te-Nb oxides employed as selective oxidation catalysts are an example of the latter $[5,6]$. 
Interestingly, simple physical mixtures of two oxides, e.g. $\mathrm{Ga}_{2} \mathrm{O}_{3}-\mathrm{WO}_{3}$ or $\mathrm{Ga}_{2} \mathrm{O}_{3}-\mathrm{MoO}_{3}$, have recently been identified as promising methanol conversion catalysts, thereby synergistically exceeding the catalytic properties of both pure oxides $[3,7]$. Nevertheless, these examples already highlight a major difficulty in mixed-oxide characterization, that is, the identification of the active working sites is even more complicated than for pure oxides and additionally comprise mixed oxidation states, phase distribution, different surface terminations, coexisting surface and bulk structures, altered local bonding geometries or the simultaneous presence of amorphous and crystalline structures [4]. From this discussion, the need to precisely know and control the structure and morphology of the respective oxide phases, and the subsequent use of dedicated well-defined and -structured model systems, is obvious. The preparation and characterization of such model systems represents a never-ending discussion, especially in the catalysis community, and are usually connected to the terms " pressure" and "materials" gaps $[8,9]$.

Although advances to overcome the material's gap have been achieved upon preparation of "inverse" model catalysts (growth of oxide on metal substrates) $[10,11]$ or the preparation of planar nano-particulate metal catalysts (e.g. well-defined metal particles supported on thin oxide substrates) [12-15], these studies suffer from the still existing pressure gap, since usually these model catalyst studies are conducted under ultra-high vacuum (UHV) conditions, i.e. in pressure regimes far from the usual technical conditions. The latter gap is increasingly circumvented by the use of high-pressure reaction cells attached to UHV chambers [16-18] or the development of in-situ high-pressure spectroscopic methods [19-23], also applicable to more technically relevant catalytic systems. The usual drawback of these industrial catalysts, nevertheless, is the presence of less-defined and -ordered particles alongside a large particle size distribution, significantly hampering detailed structural analysis. One way to overcome these problems is the use of thin film model systems, already 
successfully exploited to prepare and study the growth of small noble metal catalyst particles of e.g. Pt, $\mathrm{Rh}, \mathrm{Pd}$, Ir or Re on different templates such as $\mathrm{NaCl}, \mathrm{KCl}, \mathrm{KBr}$ or $\mathrm{MgO}$ facets [2330].

$\mathrm{NaCl}(001)$ single crystals have evolved as particularily promising materials, due to their very easy handling and use. This approach offers several advantages: The use of a well-defined and structured growth template results in very well-defined and ordered particle morphologies and structures which are ideally suited for structural analysis by electron microscopy and related techniques [30]. Studies on structural, chemical and compositional changes during catalyst activation or annealing treatments in various gas atmospheres are especially favourable due to the large contact area, especially if interfaces between oxides or oxide-metal are expected to play a dominant role. By combining these investigations with catalytic studies in a dedicated micro-reactor set-up under relevant catalytic conditions or with determination of materials properties, the establishment of structure-activity/selectivity/property correlations is greatly facilitated [31].

This method is even more powerful if these studies are also related to more industrially relevant powder systems, which can be characterized regarding structure, morphology or catalytical properties in the same experimental set-up under comparable conditions. Since so far the focus was mainly on metal particle morphology characterization after different annealing treatments and the preparation of supported metal/oxide systems [30], the present review tries to extend this thin film model concept to an in-depth discussion about the preparation of oxide films by exploiting the same properties of the growth template that led to the preparation of noble metal particles.

This knowledge-based approach offers a tremendous variety of possibilities in preparation and characterization of oxide phases, including pure oxides, the specific analysis of metalsupport interaction in oxide-supported bimetallic particles by reductive treatments and 
successful pathways to prepare model systems of mixed-oxide systems, to name just a few. In close correlation to this preparative approach, this review will show how related structural (atomic force microscopy, (scanning) electron microscopy), spectroscopic (X-ray photoelectron spectroscopy) and catalytic/property information can be gained from these thin film model systems. Such combined studies appear to be underrepresented for technologically relevant model systems so far. Wherever applicable, cross-correlations to structurally lessdefined systems are attempted.

The following contribution exemplarily reviews the possibilities of oxide model thin film preparation and analysis. Seven case study groups are presented, which cover the full range of applications of the oxide model systems in materials science and catalysis. This will encompass (1) preparation routines to well-ordered oxide films, which subsequently are compared regarding their stability under reducing conditions, (2) preparation routines to oxide nanoarchitectures, (3) studies of phase transformations between different oxide polymorphs, (4) studies of structural transformations between different oxide structures, (5) use of pure oxide model systems for catalytic studies, (6) studies of the strong metal-support interaction and the reactive formation of oxide-supported intermetallic phases and (7) preparation routines to mixed oxide phases. Details regarding the individual systems are given in the respective sections as a short introduction to the research field.

\section{Experimental Overview}

In order to prepare thin film systems applicable to both structural and spectroscopic characterization by, for example, electron microscopy techniques, X-ray photoelectron spectroscopy, atomic force microscopy as well as kinetic analysis by gas chromatography/mass spectrometry, a well-established setup is used [1]. Figure 1 shows a 
representative flow chart for the preparation of oxide thin films, which is, with small amendments, also applicable to the preparation of oxide-supported bimetallic particles and mixed-oxide films.

Pure oxide films and nano-particles were vacuum-grown on water-soluble $\mathrm{NaCl}(001)$ single crystals $\left(0.25 \mathrm{~cm}^{2}\right)$ or freshly prepared $\mathrm{NaCl}$ films (up to $100 \mathrm{~cm}^{2}$ ) by evaporation of the respective oxide in a background pressure of $\mathrm{O}_{2}$ or $\mathrm{H}_{2}$. Experimental conditions include thermal evaporation in $10^{-4}$ mbar $\mathrm{O}_{2}$ for $\mathrm{Ga}_{2} \mathrm{O}_{3}$ [32], $\mathrm{In}_{2} \mathrm{O}_{3}$ [33], $\mathrm{SiO}_{2}, \mathrm{ZnO}$ [34], $\mathrm{WO}_{3}$ [35], $\mathrm{V}_{2} \mathrm{O}_{3}$ [36], $\mathrm{Y}_{2} \mathrm{O}_{3}$ [37] and $\mathrm{GeO}_{2}[38]$ at varying template temperatures between $300-623 \mathrm{~K}$. $\mathrm{SnO}$ films were prepared in $10^{-3} \mathrm{mbar}_{2}$ due to formation of metallic $\mathrm{Sn}$ within the oxide matrix at lower oxygen pressures $[38,39] . \mathrm{Al}_{2} \mathrm{O}_{3}$ was prepared by reactive evaporation of $\mathrm{Al}$ metal in $10^{-4}$ mbar $\mathrm{O}_{2}$ [31]. The preparation of $\mathrm{SnO}_{2}$ [39], $\mathrm{V}_{2} \mathrm{O}_{5}$ [36] and $\mathrm{VO}$ [36] thin films required post-oxidation (at $673 \mathrm{~K}$ for $\mathrm{SnO}_{2}$ and $\mathrm{V}_{2} \mathrm{O}_{5}$ ) or post-reduction (at $673 \mathrm{~K}$, VO) treatments. $\mathrm{ZrO}_{2}$ films had to be prepared by thermal evaporation of $\mathrm{ZrO}_{2}$ powder in a background pressure of $10^{-5} \mathrm{mbar}_{2}$ to suppress the formation of volatile tungsten oxide species (from the W filament) [37]. Thin films of yttria-stabilized $\mathrm{ZrO}_{2}(\mathrm{YSZ})$ were prepared by sputtering from a pressed YSZ powder target. For this purpose, a home-built sputter source was used [40]. In all cases, this procedure yielded self-supporting films of $\sim 25 \mathrm{~nm}$ thickness, with the one exception $\mathrm{ZnO}$, whose preparation is hampered by its partial solubility in water. PdO particles were prepared via post-oxidation of $\mathrm{Pd}$ particles in 1 bar $\mathrm{O}_{2}$ at $673 \mathrm{~K}$ [41]. Mixed-oxide films were prepared in a similar fashion, by either co-deposition or consecutive deposition of the respective oxides [42].

Table 1 summarizes the preparation conditions for all systems studied so far. The preparation of oxide-supported bimetallic particles of $\mathrm{Pt}, \mathrm{Pd}$ and $\mathrm{Rh}$ required electron-beam deposition of the metal onto $\mathrm{NaCl}(001)$ at $623 \mathrm{~K}$ before embedding in the respective oxide matrix [43-45]. A mechanical strengthening layer of $500-1000 \mathrm{~nm} \mathrm{SiO}{ }_{2}$ was added to all films prepared on 
the polycrystalline $\mathrm{NaCl}$ films. All films were in turn floated into distilled water, dried and either mounted on gold grids for electron microscopy or mounted on quartz wool inside the micro-reactor. Formation of the thin film intermetallic phases for studying the metal-support interaction was induced by reduction treatments in hydrogen at varying temperatures between 523-573 K (Pd-based intermetallics on $\mathrm{Ga}_{2} \mathrm{O}_{3}$ [44]) or higher temperatures of $673-773 \mathrm{~K}$ (Ptbased intermetallics on $\mathrm{SiO}_{2}$ [43] and $\mathrm{Rh}$-based intermetallics on $\mathrm{VO}_{\mathrm{x}}$ [45]).

\section{Case Studies}

\subsection{Case Study 1 - Preparation of well-defined oxide films: $\mathrm{CeO}_{2}$ and $\mathrm{Y}_{2} \mathrm{O}_{3}$}

The preparation and stability of well-defined oxide thin film systems is best appreciated by a comparison of two typical representatives of this class of materials, $\mathrm{CeO}_{2}$ and $\mathrm{Y}_{2} \mathrm{O}_{3}$, which both exhibit very well-ordered structures in the initial as-grown state, but due to their inherently different chemical properties, show strong differences in their annealing and reduction behavior. Both oxides are of significant technological interest as ceramics or as catalysts in deNO $\mathrm{x}_{\mathrm{x}}$ and combustion technology [46]. A recent comprehensive review of $\mathrm{CeO}_{2}$ deals with almost all aspects of this oxide [46].

Figures $2 \mathrm{~A}$ and $2 \mathrm{~B}$ show overview transmissionm electron microscopic (TEM) images of asgrown $\mathrm{CeO}_{2}$ and $\mathrm{Y}_{2} \mathrm{O}_{3}$ thin films, respectively. Both structures are characterized by an arrangement of more or less regular grains, more rounded ones in the case of $\mathrm{CeO}_{2}$, more elongated ones for $\mathrm{Y}_{2} \mathrm{O}_{3}$. Bragg contrast is the dominate contrast mechanism, as manifested by the presence of differently oriented individual black and grey grains. The selected area electron diffraction (SAED) patterns (right insets) reveal the presence of $\mathrm{CeO}_{2}$ [47] and $\mathrm{Y}_{2} \mathrm{O}_{3}$ [37], but secondly, they reveal good ordering with respect to the former underlying $\mathrm{NaCl}(001)$ substrate. As the fcc $\mathrm{CeO}_{2}$ and the bcc $\mathrm{Y}_{2} \mathrm{O}_{3}$ structures, both exhibit only minor 
crystallographic mismatch with fcc $\mathrm{NaCl}$, the corresponding epitaxial relationships are characterized as follows:

$$
\begin{aligned}
& \mathrm{CeO}_{2}(001) / / \mathrm{NaCl}(001) \text { and } \mathrm{CeO}_{2}(110) / / \mathrm{NaCl}(110) \\
& \mathrm{Y}_{2} \mathrm{O}_{3}(001) / / \mathrm{NaCl}(001) \text { and } \mathrm{Y}_{2} \mathrm{O}_{3}(110) / / \mathrm{NaCl}(110) \text {. }
\end{aligned}
$$

High-resolution transmission electron microscopic (HRTEM) imaging additionally provides useful information on the structure and composition of the phases and corroborates the presence of fully-oxidized $\mathrm{CeO}_{2}$ and $\mathrm{Y}_{2} \mathrm{O}_{3}$. One example is shown for $\mathrm{Y}_{2} \mathrm{O}_{3}$ in the left inset of Figure 2B and reveals (211) and (125) lattice spacings of the bcc- $\mathrm{Y}_{2} \mathrm{O}_{3}$ structure. Moreover, the left inset of Figure 1A shows Moiré fringes of two overlapping, highly-oriented $\mathrm{CeO}_{2}$ grains, additionally supporting the good ordering.

However, despite their apparently strong structural similarities in the initial state, the annealing behavior and the susceptibility to structural reconstruction upon reduction strongly differs. As is well-known, $\mathrm{CeO}_{2}$ belongs to the class of rather easy reducible oxides, which is both reflected by the facts that a large number of substoichiometric $\mathrm{CeO}_{2-x}$ phases exist, and, with $\mathrm{Ce}_{2} \mathrm{O}_{3}$, another stable oxide with $\mathrm{Ce}$ in the valence state $3+$ appears in the $\mathrm{Ce}-\mathrm{O}$ system [46]. $\mathrm{Y}_{2} \mathrm{O}_{3}$, in contrast, is hardly reducible and does not form stable oxides in lower valence states [37]. We therefore anticipated rather substantial differences not only in the structure and morphology, but also in the composition of the two oxides upon annealing. Figures $2 \mathrm{C}$ and $2 \mathrm{D}$ essentially reveal that this assumption is verified.

$\mathrm{Y}_{2} \mathrm{O}_{3}$, even after reduction in flowing hydrogen at $1073 \mathrm{~K}$, shows only minor signs of sintering and the initial structure consisting of elongated grains is still visible (Figure 2D). However, the $\mathrm{CeO}_{2}$ film shows substantial reconstruction under similar reduction experimental conditions. The initial grain structure has vanished completely and been replaced by a structure consisting of elongated chips with frayed particle edges. The film 
hence does not exhibit the morphological details found after previous stages of reduction (or in the as-grown state) and it must be assumed, that a completely new structure has at least partially been formed. The SAED pattern has also changed and now shows numerous sharp rings instead of the sharp diffraction spots. By careful analysis, it is possible to distinguish some reflections of the $\mathrm{CeO}_{2}$ fcc structure, but it is not possible to assign all the rings to one structure (either sub-stoichiometric $\mathrm{CeO}_{2-\mathrm{x}}$ phases or $\mathrm{Ce}_{2} \mathrm{O}_{3}$ ). Some reflections can be assigned to $\mathrm{Ce}_{2} \mathrm{O}_{3}$ or $\mathrm{Ce}_{7} \mathrm{O}_{12}$ (as for example the triple distance of $8.7 \AA$ shown in the HRTEM inset of Figure 2C). This indicates that at least three different phases may be present. Electron-enegergy loss (EEL) spectroscopy results in fact show that a large number of $\mathrm{Ce}^{3+}$ centers are introduced after high-temperature reduction (by analysis of the $\mathrm{Ce} \mathrm{M}_{4,5}$ edge), but, in contrast, the $\mathrm{Y} \mathrm{M}_{2,3}$ edge hardly changes after similar treatments $[47,48]$.

\subsection{Case Study 2 - Preparation of oxide nano-architectures: $\mathrm{In}_{2} \mathrm{O}_{3}, \mathrm{Ga}_{2} \mathrm{O}_{3}, \mathrm{~V}_{2} \mathrm{O}_{5}$ and $\mathrm{NiO}$}

As a logical extension to what has been presented in the previous section, the outstanding properties of the $\mathrm{NaCl}(001)$ template may not only give rise to ordinary well-defined structures, but, under certain experimental circumstances, also to the formation of nanoarchitectures of distinct shape and morphology. The exemplified discussion and comparison of four representatives of this oxide group shows the capabilities of $\mathrm{NaCl}(001)$, going well beyond the presence of simple crystallographic relations. Whereas the latter is useful for the formation of pyramidal-shaped $\mathrm{In}_{2} \mathrm{O}_{3}$ particles [33] (Figure 3A) and for $\mathrm{NiO}$ particles exhibiting regular voids within their morphology (Figure 3D), the formation of spherical $\mathrm{Ga}_{2} \mathrm{O}_{3}$ particles [32] (Figure 3B) and oblong, needle-like $\mathrm{V}_{2} \mathrm{O}_{5}$ morphologies [49] (Figure 3C) cannot be explained by simple epitaxial relations between $\mathrm{NaCl}$ and the respective oxide structure. Rather, the energetic situation at the oxide $/ \mathrm{NaCl}(001)$ interface is held additionally responsible for the formation of these distinct architectures. In the case of $\mathrm{Ga}_{2} \mathrm{O}_{3}$, this likely 
includes a complex equilibrium between formation and re-oxidation of sub-stoichiometric $\mathrm{GaO}_{\mathrm{x}}$ entities [32]. All four oxides have widespread application possibilities, encompassing the full technological spectrum from materials science to catalysis.

$\mathrm{In}_{2} \mathrm{O}_{3}$ has been shown to be a promising $\mathrm{CO}_{2}$-selective catalyst in methanol or ethanol steam reforming as well as being active in $\mathrm{deNO}_{\mathrm{x}}$ reaction using hydrocarbons [49]. Its most widespread application lies within optoelectronics as a constituent of indium-tin-oxide (ITO) materials $[33,50] . \mathrm{Ga}_{2} \mathrm{O}_{3}$ is a multi-talented oxide with applications as sensors, optoelectronic devices and catalysis, including hydrocarbon isomerization, dehydrogenation and aromatization or methanol synthesis [32]. For both oxides, a well-established set of chemical and physical procedures for model system preparation exists, including sputtering, laser deposition, chemical vapor deposition, electrochemical deposition, spray pyrolysis and surface oxidation of precursor species $[1,32,33]$.

$\mathrm{VO}_{\mathrm{x}}$-based systems are among the most widely used catalyst systems in industrial chemical processes, e.g. for the oxidation of $\mathrm{SO}_{2}$ to $\mathrm{SO}_{3}$ during the production of sulphuric acid or as part of the heterogeneous version of the Wacker process, i.e. the oxidation of ethene to acetaldehyde and acetic acid [1,49]. NiO plays an important role for all Ni-containing catalyst systems; its stability in hydrogen crucially influences the catalytic performance [51].

Nano-pyramidal particles, as shown in Figure 3A, can be obtained by depositing $\operatorname{In}_{2} \mathrm{O}_{3}$ onto $\mathrm{NaCl}(001)$ at $573 \mathrm{~K}$ [32]. The strong ordering of the particles is corroborated by the SAED patterns (right inset), which show almost single-crystalline ordering of the bcc- $\operatorname{In}_{2} \mathrm{O}_{3}$ structure. The lattice mismatch between bcc $\operatorname{In}_{2} \mathrm{O}_{3}$ and $\mathrm{NaCl}(001)$ is less than $11 \%$. Dark-field images reveal the pyramidal shape of the $\mathrm{In}_{2} \mathrm{O}_{3}$ particles, as deduced from the appearance of the characteristic height contour lines (note the inset at the top right corner). The necessity of $\mathrm{NaCl}(001)$ to grow these characteristic morphologies is further corroborated by similar experiments on sapphire sheets, where due to the missing epitaxial relations, only irregular 
morphologies have been obtained [32]. These special $\operatorname{In}_{2} \mathrm{O}_{3}$ architectures can also be used as supports for noble metal catalyst particles to gain access to nano-architectured metal-oxide systems of defined shape. The left inset thus shows such an entity, with Pd particles decorating the well-shaped $\operatorname{In}_{2} \mathrm{O}_{3}$ particles. This system was prepared by depositing $\mathrm{Pd}$ particles at $573 \mathrm{~K}$ directly onto the previously $573 \mathrm{~K}$ deposited $\mathrm{In}_{2} \mathrm{O}_{3}$ particles.

The formation of $\mathrm{Ga}_{2} \mathrm{O}_{3}$ nanospherical particles occurs only after deposition of $\mathrm{Ga}_{2} \mathrm{O}_{3}$ at 573 $\mathrm{K}$ (Figure 3B) [32], whereas an irregular structure persists at lower template temperatures. The sphere-like particles can also be nicely seen in AFM images (left inset), obtained on the free-standing film, already mounted on gold grids for electron microscopy [32]. As the corresponding SAED pattern is amorphous, epitaxial relations do not play a dominant role in the formation of the spheres, rather they are the result of a delicate balance between formation, desorption and re-oxidation of sub-stoichiometric $\mathrm{GaO}_{\mathrm{x}}$ species. These highly volatile species are thought to form during the deposition process due to $\mathrm{Ga}_{2} \mathrm{O}_{3}$ oxygen loss and are subsequently re-oxidized. If the re-oxidation is much faster than desorption, small spheres result and agglomeration by Ostwald-ripening is suppressed. In contrast, if the oxygen pressure is small, and hence, the re-oxidation rate slow, larger spheres result. This has been shown by defined variation of the oxygen partial pressure [32]. The formation of the spheres therefore is intimately connected to the wetting and energetic behavior of the $\mathrm{GaO}_{\mathrm{x}}, \mathrm{Ga}_{2} \mathrm{O}_{3}$ and $\mathrm{NaCl}(001)$ interface and resembles the rheotaxial growth and thermal oxidation (RGTO) mechanism described by Sberveglieri et al. [52]. The latter, successfully proven for $\mathrm{SnO}_{2}$, is a two-step process involving the formation of a metallic nanoparticle, followed by subsequent thermal oxidation at high temperatures. In the present case, the reactive growth involves substoichiometric $\mathrm{GaO}_{\mathrm{x}}$ entities. It should be noted, that although the formation of distinct morphologies for $\mathrm{In}_{2} \mathrm{O}_{3}$ and $\mathrm{Ga}_{2} \mathrm{O}_{3}$ is due to seemingly different mechanisms, in both cases the problems which are usually faced upon preparation of such nanomaterials are overcome; 
that is, the very high template temperatures. For $\operatorname{In}_{2} \mathrm{O}_{3}$, typically, temperatures $\mathrm{T}>1000 \mathrm{~K}$ are necessary [53].

$\mathrm{V}_{2} \mathrm{O}_{5}$-nanoparticulate systems can be obtained by growing $\mathrm{V}_{2} \mathrm{O}_{3}$ on $\mathrm{NaCl}(001)$ at $573 \mathrm{~K}$ and subsequent post-oxidation at temperatures above $673 \mathrm{~K}$ [36]. The change in oxidation state from $\mathrm{V}_{2} \mathrm{O}_{3}$ to $\mathrm{V}_{2} \mathrm{O}_{5}$ (SAED pattern shown as right inset in Figure 3C) is accompanied by a morphological transition from a rounded-grain to a plate-like structure. Further oxidation at $\mathrm{T}$ $\geq 773 \mathrm{~K}$ results in the formation of oblong particles and needle-like arrangements (Figure 3 C). This is useful from three points of view: firstly, it is obviously possible to trigger the morphology of $\mathrm{V}_{2} \mathrm{O}_{5}$ by simply altering the oxidation temperature. Secondly, subsequent reduction treatments also offer the possibility to switch from $\mathrm{V}_{2} \mathrm{O}_{5}$ over $\mathrm{V}_{2} \mathrm{O}_{3}$ to $\mathrm{VO}$ particles. The latter, for example, exhibits a characteristic porous structure obtained after reduction at $673 \mathrm{~K}$. In the third place, as shown in the left inset, the $\mathrm{V}_{2} \mathrm{O}_{5}$ nanoarchitectures can be used as templates for small noble metal particles (e.g. Pd), resulting in more complex supported architectured metal/oxide systems, very similar to $\mathrm{Pd}$ on $\operatorname{In}_{2} \mathrm{O}_{3}$. Such systems can, for example, be prepared by depositing $\mathrm{Pd}$ particles on $\mathrm{NaCl}(001)$ first, subsequently embedding them in $\mathrm{V}_{2} \mathrm{O}_{3}$ and applying the same oxidation procedures [49]. Hence, this represents another example of a simple, effective and reproducible pathway to such systems without extended chemical procedures.

Finally, a slightly different preparation pathway leads to distinct porous NiO structures. Starting with the deposition of small $\mathrm{Ni}$ particles on $\mathrm{NaCl}(001)$ at $573 \mathrm{~K}$, subsequent oxidation at temperatures $\mathrm{T} \geq 573 \mathrm{~K}$ yields well-ordered holey $\mathrm{NiO}$ particles, as proven by SAED patterns and EEL spectroscopy (see the right and left inset of Figure 3D). The resulting voids can be easily seen in high-angle annular dark field (HAADF) images (Figure 3D). The effect of void formation in oxide particles usually is summarized under the term "nanoscale Kirkendall effect", a solid-state diffusional, interface-controlled process leading to distinct 
core-shell structures [54]. Void formation in $\mathrm{NiO}$ is a fully reversible process, leading to solid $\mathrm{Ni}$ particles after annealing porous $\mathrm{NiO}$ at $673 \mathrm{~K}$.

3.3. Case Study 3 - Structural transformations between different oxide polymorphs: $\mathrm{WO}_{3}$ and $\mathrm{ZrO}_{2}$

A further extension of the use of oxide films deposited on $\mathrm{NaCl}(001)$ are studies of phase transformations between different polymorphic forms and structures. Understanding and characterization of these transitions is of tremendous importance in many applications fields from technological aspects to catalysis. Phase transformations within the $\mathrm{ZrO}_{2}$ system are known to have a crucial influence of the stability of ceramic coatings [55], whereas the large number of tungsten oxides exhibit different behavior in sensor properties and catalytic performance [35]. The thermodynamically stable phases of both $\mathrm{ZrO}_{2}$ and $\mathrm{WO}_{3}$ are monoclinic structures $[35,37]$. However, with the use of the $\mathrm{NaCl}(001)$ template, access to other, less stable, oxide polymorphs is provided with the possibility to identify the determining parameters governing the eventual phase transitions.

Figures 4A - 4C show how electron microscopy and selected area electron diffraction can be used to follow the transition from amorphous $\mathrm{WO}_{3}$ (compare the SAED pattern shown in the inset of Figure $4 \mathrm{~A}$ as well as the W $4 \mathrm{f}$ XPS spectrum of the film in the left inset: for comparison the $\mathrm{W} 4 \mathrm{f}$ doublet of metallic $\mathrm{W}$ is shown in red) over monoclinic $\mathrm{WO}_{3}$ after oxidation at $673 \mathrm{~K}$ to an hexagonal $\mathrm{WO}_{3}$ phase, formed after oxidation at $773 \mathrm{~K}$ [35]. This phase transformation is accompanied by pronounced changes in the film structure and morphology. Starting from a porous structure, the monoclinic $\mathrm{WO}_{3}$ phase is characterized by large, strained islands with a defined SAED pattern (left inset in Figure 4B). A highresolution image (inset in right side of Figure 4B) shows such a structurally-defective, strained island in detail. The hexagonal structure is characterized by low-contrast platelets with darker edges. On one of these patches, the single-crystalline SAED pattern (right inset), 
as well as the high-resolution detail (right inset, lattice fringes of $\sim 6 \AA$, associated with hex$\mathrm{WO}_{3}(100)$ lattice spacings are clearly visible) has been obtained. The darker, star-like patches are exclusively associated with monoclinic $\mathrm{WO}_{3}$. Therefore, the transition between the different polymorphic forms of $\mathrm{WO}_{3}$ is structurally and crystallographically very complex and it is not straightforward to obtain single polymorphic forms.

That it is indeed possible to switch between different structurally almost phase-pure polymorphic oxide modifications, is exemplarily shown for the $\mathrm{ZrO}_{2}$ system. Here, the initial oxide film is again amorphous (Figure 4D), but annealing at $673 \mathrm{~K}$ induces a substantial structural reconstruction into plates and large-area grains (Figure 3E), characteristic of tetragonal $\mathrm{ZrO}_{2}$, as confirmed by the SAED pattern (inset in 3E). Further annealing at temperatures $\mathrm{T}>773 \mathrm{~K}$ yields another phase transformation into monoclinic $\mathrm{ZrO}_{2}$ (Figure $4 \mathrm{~F}$ and SAED inset). While it is not particularly astonishing that after deposition at $300 \mathrm{~K}$ an amorphous form is initially present, the appearance of a tetragonal structure, usually only accessible via stabilizing agents (such as $\mathrm{Y}$, leading to yttria-stabilized $\mathrm{ZrO}_{2}$ ), was not anticipated. However, also in this case, $\mathrm{NaCl}$ is assumed to basically act as a structural mediator, favoring the stabilization of tetragonal $\mathrm{ZrO}_{2}$ over other polymorphic forms [37]. The use of these $\mathrm{ZrO}_{2}$ model systems also offers a convenient way to study the martensitic tetragonal $\rightarrow$ monoclinic phase transformation, observed after annealing at $1073 \mathrm{~K}$, in detail. This diffusionless, athermic transformation is associated with shear movements of the entire structure, finally leading to cracks in the structure and an associated volume increase [55]. The strain fields, being easily visible in Figure 4F, are typical manifestations of this particular transition.

3.4. Case Study 4 - Structural transformations between different oxide structures: $\mathrm{V}_{2} \mathrm{O}_{3}, \mathrm{SnO}_{2}$ and $\mathrm{CuO}$ 
A further manifestation of the capabilities of thin film oxide models grown on $\mathrm{NaCl}(001)$ is presented in studies on the transition between oxides with different valences. This is exemplified in detail for two technologically and catalytically important classes of oxides, namely $\mathrm{SnO}_{\mathrm{x}}$ and $\mathrm{VO}_{\mathrm{x}}$, with a short perspective view on $\mathrm{CuO}$. In all three cases, a sequence of oxidation and reduction treatments allows to easily switch between different oxidation states of either tin, vanadium or copper, and to subsequently prepare an array of single oxide phases whose properties can be studied [36,38]. This is especially important for $\mathrm{SnO}_{2}$, one the best studied oxides so far, with almost all aspects of its surface and materials properties covered in a recent review [56]. It is also worthwhile to mention that $\mathrm{SnO}_{2}$ is the archetypical system for preparation via rheotaxial growth and thermal oxidation (that is deposition of $\mathrm{Sn}$ metal followed by oxidation to induce oxide formation [52]), a concept which has been discussed for $\mathrm{Ga}_{2} \mathrm{O}_{3}$ spheres in section 3.2.

Regarding the Sn-O system, deposition of $\mathrm{SnO}_{2}$ in $10^{-3}$ mbar oxygen at $573 \mathrm{~K}$ leads to the formation of a single well-ordered cubic $\mathrm{SnO}$ phase (Figure 5A) [38]. Post-oxidation treatments at elevated temperatures in air (at and above $673 \mathrm{~K}$ ) cause the formation of $\mathrm{SnO}_{2}$ (Figure 5B), exhibiting a structure consisting of interconnected regular rounded grains. Reduction of this phase in hydrogen at $673 \mathrm{~K}$ yields precipitation of a metallic $\beta$-Sn phase, characterized by very large $(\sim 50-100 \mathrm{~nm})$ irregular particles. Whereas the transformation between $\mathrm{SnO}_{2}$ and $\mathrm{SnO}$ is fully reversible, the transformation to $\beta$-Sn cannot be reversed due to the substantial rupture of the film structure [38]. EEL spectroscopy is a particular rewarding technique to follow the transition $\mathrm{Sn}^{4+} \rightarrow \mathrm{Sn}^{2+} \rightarrow \beta$-Sn. Representative examples are provided as insets in Figure 5B, all exhibiting the typical oxygen K-edge energy-loss near edge structural (ELNES) features of the participating tin phases [38].

Extension of these studies to the $\mathrm{VO}_{\mathrm{x}}$ system yields a convenient pathway for the preparation of at least three oxide phases: $\mathrm{V}_{2} \mathrm{O}_{3}, \mathrm{~V}_{2} \mathrm{O}_{5}$ and $\mathrm{VO}$ [36]. Whereas the formation of specific 
$\mathrm{V}_{2} \mathrm{O}_{5}$ nanoarchitectures has been already addressed in section 3.2., the focus in this section lies entirely on the experimental conditions to prepare single-phase $\mathrm{VO}_{\mathrm{x}}$. As shown in Figure $6 \mathrm{~A}$, deposition of $\mathrm{V}$ metal in $10^{-4}$ mbar oxygen leads to well-ordered $\mathrm{V}_{2} \mathrm{O}_{3}$ phases (cf. SAED pattern shown as an inset). Exact monitoring of the deposition parameters, i.e. oxygen partial pressure and deposition rate, is crucial since $\mathrm{V}_{2} \mathrm{O}_{3}$ is only obtained at rather high oxygen partial pressures and comparatively slow rates. Violating these experimental rules inevitably causes formation of mixed $\mathrm{V}_{2} \mathrm{O}_{3} / \mathrm{VO}$ phases, and in extreme cases, the formation of metallic vanadium. Subsequent oxidation at $673 \mathrm{~K}$ yields single-phase $\mathrm{V}_{2} \mathrm{O}_{5}$, whose structure - due to its monoclinic lattice - is not particularly well ordered. What makes the use of thin film systems in this particular case even more attractive, is to follow the phase transition not only by electron diffraction, but also by monitoring the structure and morphology of the film. $\mathrm{V}_{2} \mathrm{O}_{5}$ exhibits a very characteristic structure consisting of elongated large-area (up to $50 \mathrm{~nm}$ in size) grains which are entirely different from the regular grain structure of $\mathrm{V}_{2} \mathrm{O}_{3}$ (Figure 6B). VO, in contrast, can be prepared by reduction of $\mathrm{V}_{2} \mathrm{O}_{5}$ in hydrogen at temperatures at and above $673 \mathrm{~K}$ (Figure 6C). Although the overall morphology of $\mathrm{V}_{2} \mathrm{O}_{5}$ appears to be retained, the $\mathrm{VO}$ structure is characterized by a porous, almost amorphous microstructure, as evidenced by the SAED pattern (inset). The same VO structure can also be obtained by reduction of the $\mathrm{V}_{2} \mathrm{O}_{5}$ structure in the electron beam of an electron microscope, which in principle allows monitoring the phase transformation $\mathrm{V}_{2} \mathrm{O}_{5} \leftrightarrows \mathrm{VO}$ in-situ [57]. Also in this case, EEL spectroscopy is the perfect tool to follow the electronic changes upon phase transformation. Both the oxygen-K edge and the intensity ratio between the vanadium- $\mathrm{L}_{3}$ and $\mathrm{L}_{2}$ edges exhibit characteristic features that allow the assignment to one of the different oxide phases [36].

Similar concepts also hold for other systems, e.g. the $\mathrm{Cu}-\mathrm{O}$ system, where insights into the transition $\mathrm{Cu} \rightarrow \mathrm{Cu}_{2} \mathrm{O} \rightarrow \mathrm{CuO}$ can be obtained, especially to answer the question of whether a direct transition from $\mathrm{CuO}$ to $\mathrm{Cu}$ metal is possible; there is controversy on this issue in the 
literature [58]. Associated experiments using the thin film system indicate that $\mathrm{Cu}_{2} \mathrm{O}$ is always formed upon either oxidation of $\mathrm{Cu}$ metal or reduction of $\mathrm{CuO}$, at least for nano-particulate systems [59].

\subsection{Case Study 5 - Use of oxide model systems for catalytic studies: $\mathrm{In}_{2} \mathrm{O}_{3}$ and $\mathrm{Ga}_{2} \mathrm{O}_{3}$}

The correlation between structure and catalytic activity/selectivity, i.e. the establishment of structure-activity relationships, is where the thin film pathway unfolds its highest strength. In cases for which the results obtained on the thin film can furthermore be directly correlated to measurements on technologically relevant powder systems, a clear picture of the particular catalytic system evolves. This procedure is exemplified for two oxide systems, which attracted increased interest previously as supports for catalytic active and selective Pd-based intermetallic phases, that is, $\mathrm{In}_{2} \mathrm{O}_{3}[44]$ and $\mathrm{Ga}_{2} \mathrm{O}_{3}$ [60]. These cases therefore provide a direct validation of the thin film concept.

Figure 7 shows a compact overview of the catalytic action of the $\operatorname{In}_{2} \mathrm{O}_{3}$ thin film in methanol steam reforming following the reaction

$$
\mathrm{CH}_{3} \mathrm{OH}+\mathrm{H}_{2} \mathrm{O} \rightleftharpoons \mathrm{CO}_{2}+3 \mathrm{H}_{2}
$$

in contrast to simple methanol dehydrogenation

$$
\mathrm{CH}_{3} \mathrm{OH} \rightleftharpoons \mathrm{CO}+2 \mathrm{H}_{2} \text {. }
$$

$\mathrm{In}_{2} \mathrm{O}_{3}$ itself turned out to be a highly selective methanol steam reforming catalyst, providing $\mathrm{CO}_{2}$-selectivities of up to $95 \%$. This is verified both on thin film samples (lower left panel) as well as on the respective powder system (lower right panel). The structure of the thin film system used as catalyst is represented in the TEM image (upper panel), further providing In$\mathrm{M}_{4,5}$ and oxygen-K EEL edges and SAED patterns to confirm the $\operatorname{In}_{2} \mathrm{O}_{3}$ stoichiometry of the 
initial catalyst $[33,44]$. In turn, the thin film model allows one to follow the impact of the reaction mixture (methanol+water) on the structure directly by TEM and by connecting the experiments to the powder sample, to unambiguously elucidate the reason for its peculiar $\mathrm{CO}_{2}$ selectivity. In short, $\operatorname{In}_{2} \mathrm{O}_{3}$ is highly susceptible to be reduced by $\mathrm{CO}$ and to subsequently form $\mathrm{CO}_{2}$ in a Mars-van-Krevelen-type reaction mechanism [61]. In contrast, replenishment of the introduced oxygen vacancies by $\mathrm{CO}_{2}$ is strongly suppressed. As the inverse water-gas shift reaction as a selectivity-spoiling reaction in methanol steam reforming (MSR) is therefore also blocked and formaldehyde, as the crucial reaction intermediate in methanol steam reforming, is also rapidly converted to $\mathrm{CO}_{2}$ with a very similar selectivity pattern. Thus, $\mathrm{In}_{2} \mathrm{O}_{3}$ evolves as a promising $\mathrm{CO}_{2}$-selective MSR catalyst [44,61].

For $\mathrm{Ga}_{2} \mathrm{O}_{3}$, the catalytic scenario is more complex, due to its ability to catalyze the water-gas shift reaction rather efficiently. It was found to proceed via two parallel mechanisms, a formate-mediated and a vacancy mediated mechanism, depending on the reaction temperature and sample pre-treatment $[60,62]$. As shown in Figure 8 for the behavior of a $\mathrm{Ga}_{2} \mathrm{O}_{3}$ thin film in methanol steam reforming, in contrast to $\mathrm{In}_{2} \mathrm{O}_{3}, \mathrm{Ga}_{2} \mathrm{O}_{3}$ is unselective and formic acid additionally appears as a reaction intermediate. This is basically due to differences in surface chemistry between $\mathrm{Ga}_{2} \mathrm{O}_{3}$ and $\mathrm{In}_{2} \mathrm{O}_{3}$, steering the MSR selectivity in different directions. Following a recent proposal by Tatibouet to explain the selectivity patterns in methanol oxidation [63], $\mathrm{In}_{2} \mathrm{O}_{3}$ is a more basic oxide and tends to form more totally oxidized products, whereas $\beta-\mathrm{Ga}_{2} \mathrm{O}_{3}$ is a redox-active and amphoteric oxide, without pronounced basic or acidic character, and provides a compromise between partially oxidized species like CO, formaldehyde or formic acid (and its derivatives, such as formic acid methyl ester). A TEM image of a $\mathrm{Ga}_{2} \mathrm{O}_{3}$ thin film, which was used as a catalyst (deposited at $300 \mathrm{~K}$ onto $\mathrm{NaCl}(001))$, is shown in the upper inset and exhibits a rather low-contrast structure due to its 
amorphous nature. XPS spectra taken after different oxidation, reduction and catalytic treatments reveal that the bulk stoichiometry is always close to $\mathrm{Ga}_{2} \mathrm{O}_{3}$ (bottom inset).

\subsection{Case Study 6 - Studies on the strong metal-support interaction - Reductive formation of intermetallic phases: $\mathrm{Pt} / \mathrm{SiO}_{2}, \mathrm{Pd} / \mathrm{Ga}_{2} \mathrm{O}_{3}$ and $\mathrm{Rh} / \mathrm{VO}_{x}$}

The present section will show how the use of the thin film model systems can provide insights into one of the core-topics in catalysis, metal-support interaction, which goes beyond the simple studies of isolated pure oxides. Strong metal-support interaction (SMSI) has always been a hot topic in catalysis and is historically related to the interaction of noble metals, such as $\mathrm{Rh}$, $\mathrm{Pt}$ or $\mathrm{Pd}$ with reducible oxides $\left(\mathrm{TiO}_{2}, \mathrm{CeO}_{2}\right.$, among others) upon hydrogen treatments at elevated temperatures [64]. However, nowadays it is widely accepted that other oxides such as $\mathrm{SiO}_{2}$ or $\mathrm{Al}_{2} \mathrm{O}_{3}$, may also enter a state of strong metal-support interaction under special experimental circumstances. Common structural manifestations of strong metal-support interactions comprise, for example, charge transfer effects or encapsulation/decoration of metal particles by reduced support species. As an extreme case usually observed at very high temperatures, partial or complete alloying/formation of intermetallic phases is also included [64-66]. However, strong metal-support interaction in general and formation of intermetallic phases upon high-temperature reduction of supported systems has up to now mostly been considered as having a detrimental effect on the catalytic entity (e.g., by covering active metal surface area by encapsulation).

Recently, the use of intermetallic phases in catalysis has seen a revival in a number of research fields and much focus is placed on the preparation of these potentially catalytically active phases [67]. One particular promising and very often used preparation pathway to intermetallic phases is via hydrogen reduction of an oxide-supported noble metal. Depending 
on the system, very high reduction temperatures may be required to induce intermetallic formation. Furthermore, it is to be noted that this intermetallic phase is then on a more or less reduced support implying that all the associated adlineation or metal-oxide phase boundary effects must be extended to the intermetallic-support contact area, with possible implications on the catalytic behavior of the entire structural entity. In summary, the actual catalytically active state of such catalysts appears to be a combination of several potentially active sites, encompassing intermetallic, intermetallic-oxide interface and the more or less reduced state of the oxide support itself.

Knowledge about the mechanism of intermetallic formation and the structure of the (inter-) phases is therefore imperative. In the following, by the use of three types of metal-oxide thin film model catalysts, it is exemplarily shown how extremely variable the formation of the intermetallic phase can be and what catalytic implications these variations in formation conditions have. The first system, $\mathrm{Pt} / \mathrm{SiO}_{2}$, shows how $\mathrm{SiO}_{2}$ can be converted into a "SMSI" oxide by simply exploiting the thin film approach and the associated larger contact area to aid the formation of epitaxial formation of a $\mathrm{Pt}_{3} \mathrm{Si}$ intermetallic phase at surprisingly low reduction temperatures [43]. Secondly, studies on the $\mathrm{Pd} / \mathrm{Ga}_{2} \mathrm{O}_{3}$ system reveal how the extent of intermetallic formation will affect the oxidative re-activation of the catalyst system and the subsequent use as a catalyst in methanol steam reforming $[44,60]$. Thirdly, the direct impact of Rh-V intermetallic formation on the catalytic performance of $\mathrm{CO}$ hydrogenation activityand selectivity is highlighted for $\mathrm{Rh} / \mathrm{VO}_{\mathrm{x}}$ thin film systems $[45,68]$.

Figure 9A shows the $\mathrm{Pt} / \mathrm{SiO}_{2}$ thin film model catalyst before reduction. Very regular mostly square- and rectangular-shaped particles Pt particles are encountered, as also confirmed by the SAED pattern (right inset). High-resolution TEM images of single particles (left inset) usually exhibit (200) lattice fringes running $45^{\circ}$ to the particle edges. From related dark-field TEM images, the morphology of the particles can be deduced as truncated octahedral [27]. After 
reduction at $873 \mathrm{~K}$ (Figure 9B), however, considerable structural changes are introduced. Particles with sharp edges are frequently encountered (a), as well as very large ones (b), both marked by arrows. The SAED pattern (left inset) shows additional spots of a well-ordered structure besides additional ring reflections. The former arise from the presence of an epitaxially grown $\mathrm{Pt}_{3} \mathrm{Si}$ intermetallic compound, which has formed during reduction. HRTEM images now show the (200) reflections of the $\mathrm{Pt}_{3} \mathrm{Si}$ phase running parallel to the particle edges, inferring also a morphological change of the particles. In fact, dark-field images show considerable flattening of the particles [48].

The impact of intermetallic formation on the oxide support itself can be followed by EEL spectroscopy. Careful analysis shows that the electronic structure of reduced $\mathrm{SiO}_{2}$, analyzed close to the particle, has been significantly altered in comparison to on the support and close to the particle before reduction. This indicates that the formation of the intermetallic phase proceeds via reduction of the support and diffusion of Si to the Pt lattice, preceding local epitaxial growth [43]. The same concept can also be applied to a number of other thin film systems, including $\mathrm{Pt} / \mathrm{Al}_{2} \mathrm{O}_{3}$ and $\mathrm{Pt} / \mathrm{CeO}_{2}[69]$.

Intermetallic formation in the $\mathrm{Pd} / \mathrm{Ga}_{2} \mathrm{O}_{3}$ system, in contrast, appears to be more complex. Fueled by the properties of a range of oxide-supported Pd-based intermetallic phases in $\mathrm{CO}_{2}$ selective methanol steam reforming [70], Figure 10 in turn reveals not only the complexity of intermetallic formation, but also how the decomposition of the intermetallic compound (i.e. oxidative catalyst re-generation) is dependent on the local pre-reduction history [44].

In Figure 10A, Pd particles epitaxially grown on $\mathrm{NaCl}(001)$ (see inset of SAED pattern) are embedded in amorphous $\mathrm{Ga}_{2} \mathrm{O}_{3}$ (deposited at $573 \mathrm{~K}$ after Pd deposition). Reduction at $673 \mathrm{~K}$ induces considerable sintering as well as the almost complete formation of a well-ordered $\mathrm{Pd}_{5} \mathrm{Ga}_{2}$ intermetallic phase (Figure 10C). Intermetallic formation sets in already at $523 \mathrm{~K}$, but at lower temperatures, only mixtures of metallic $\mathrm{Pd}$ and $\mathrm{Pd}_{5} \mathrm{Ga}_{2}$ are present. Likewise, 
oxidation of the as-formed intermetallic compounds reveal a complex behavior. Oxidation at $673 \mathrm{~K}$ of a Pd-based bimetallic formed at $523 \mathrm{~K}$ (that is, incomplete intermetallic formation) causes complete decomposition into $\mathrm{PdO} / \mathrm{Pd}$, whereas an intermetallic formed at $673 \mathrm{~K}$ (and higher temperatures) only transforms back to metallic Pd. According to the TEM images (Figure 10B and 10D), this is due to increased mobility of Ga and the subsequent formation of a $\mathrm{Ga}_{2} \mathrm{O}_{3}$ barrier layer around the metallic particle core, preventing further oxidation to PdO (two core-shell particles have been noted by arrow in Figure 10D). As none of these features have been observed for the impregnated $\mathrm{Pd} / \mathrm{Ga}_{2} \mathrm{O}_{3}$ catalysts, the formation of this layer is attributed to the extended (inter-)metal(ic)-support contact area in the case of the thin film model.

Catalyst re-use is therefore also dependent on the pre-reduction history. At the same temperature range in which single-phase $\mathrm{Pd}_{5} \mathrm{Ga}_{2}$ is formed in the thin film system upon reduction in hydrogen $(523-673 \mathrm{~K})$, methanol dehydrogenation to $\mathrm{CO}$ is effectively suppressed in favour of $\mathrm{CO}_{2}$-selective steam reforming. The establishment of structureactivity/selectivity correlations must therefore include strong (inter-)metal-support interaction effects such as intermetallic particle decoration by reduced oxide supports, which suppresses formation of $\mathrm{CO}_{2}$ and generally deactivates the catalyst due to encapsulation of catalytically active intermetallic particles by mobile $\mathrm{GaO}_{\mathrm{x}}$ species $\left(\mathrm{Ga}_{2} \mathrm{O}_{3}\right.$ itself is active, but $\mathrm{CO}_{2^{-}}$ unselective in methanol steam reforming) [60]. Note that these effects are only made visible using the thin film system.

To further extend these studies to a more general discussion about different types of strong metal-support interaction, the capabilities of the thin film model approach in studying hightemperature reduction effects observed for different $\mathrm{Rh} / \mathrm{VO}_{\mathrm{x}}$ thin film model catalysts and the subsequent establishment of structure-activity correlations in CO hydrogenation are briefly discussed $[45,68] . \mathrm{Rh} / \mathrm{VO}_{\mathrm{x}}$ catalysts with different $\mathrm{VO}_{\mathrm{x}}$ thicknesses $(0-25 \mathrm{~nm})$ and an 
"inverse" model catalyst ( $\mathrm{VO}_{\mathrm{x}}$ prior to $\mathrm{Rh}$ deposition) were screened for this purpose. In the as-grown states, higher $\mathrm{VO}_{\mathrm{x}}$ coverages $(\geq 3 \mathrm{~nm})$ without exception result in crystalline $\mathrm{V}_{2} \mathrm{O}_{3}$ phases in epitaxial relation to the Rh particles. Lower exposures yield less-ordered layers of cubic VO. Subsequently, also after oxidation at $673 \mathrm{~K}$, the oxidation state of V varies between $\mathrm{V}^{2+}$ and $\mathrm{V}^{5+}$, depending on the film thickness. Figure 11 (bottom panels A-D) exemplarily shows the states of the catalyst with a $25-\mathrm{nm}$-thick $\mathrm{VO}_{\mathrm{x}}$ layer after different oxidation and reduction treatments, marked in the upper panel by A-D corresponding to the image.

After initial oxidation at $673 \mathrm{~K}$, the oxide structure can be characterized as $\mathrm{V}_{2} \mathrm{O}_{5}$. Below reduction temperatures of $573 \mathrm{~K}$, decoration of $\mathrm{Rh}$ particles by reduced $\mathrm{VO}_{\mathrm{x}}$ species is the dominant effect of metal-support interaction on all catalysts (bottom panels B-C) and VO is the dominate oxide phase. Higher reduction temperatures favour the formation of defined intermetallic phases on all catalysts, except on the "inverse" catalyst, where decoration is predominantly observed up to $673 \mathrm{~K}$. The TEM image of bottom panel $\mathrm{C}$ (after reduction at $773 \mathrm{~K}$ ) shows that reduction of the $\mathrm{Rh} / \mathrm{V}_{2} \mathrm{O}_{5}$ catalyst leads to full transformation of $\mathrm{V}_{2} \mathrm{O}_{5}$ into $\mathrm{VO}$ and associated strong sintering of the former Rh particles, thereby also entering a $\mathrm{V}_{3} \mathrm{Rh}_{5}$ intermetallic state. Regarding catalytic activity in $\mathrm{CO}$ hydrogenation reactions

$$
n C O+(3 n+1) H_{2} \rightleftharpoons C_{n} H_{2 n+2}+H_{2} O \text { (for alkane formation) }
$$

and

$$
n \mathrm{CO}+3 n \mathrm{H}_{2} \rightleftharpoons \mathrm{C}_{n} \mathrm{H}_{2 n}+n \mathrm{H}_{2} \mathrm{O} \text { (for alkene formation) }
$$

(as shown in the upper panel), the observed initial decrease of activity between 373 and $473 \mathrm{~K}$ is associated with the loss of active $\mathrm{Rh}$ area by decoration with reduced $\mathrm{VO}_{\mathrm{x}}$ species. At these temperatures, no intermetallic formation is observed. 
Increasing deactivation above $573 \mathrm{~K}$ reduction temperature was ascribed to the formation of distinct Rh-V bulk intermetallic phases [44]. Along with this loss of activity, however, goes a considerable selectivity shift to methane (see the inset in the upper panel). Although this is in agreement with previous studies on inverse model catalysts, this trend towards methane can also be associated with the loss of $\mathrm{Rh}-\mathrm{VO}_{\mathrm{x}}$ interface, which should generally inhibit formation of longer hydrocarbon chains. Furthermore, Figure 11 also shows how the thin film model system can be used to study the regeneration of $\mathrm{Rh} / \mathrm{VO}_{\mathrm{x}}$ catalysts. $\mathrm{V}_{3} \mathrm{Rh}_{5}$ formation is reversed by oxidation at $673 \mathrm{~K}$ (bottom image $\mathrm{D}$ ), where both the plate-like $\mathrm{V}_{2} \mathrm{O}_{5}$ structure and the former $\mathrm{Rh}$ particle sizes are partially recovered. Along with this structural recovering goes an increase of the CO turnover frequency (TOF) value in $\mathrm{CO}$ hydrogenation up to half of the initial value before reduction [68] and a shift back in selectivity to longer-chain hydrocarbons.

3.8. Case study 7: Preparation and characterization of mixed oxide systems: $\mathrm{Ga}_{2} \mathrm{O}_{3}-\mathrm{WO}_{3}$ and $\mathrm{Y}_{2} \mathrm{O}_{3}$-stabilized $\mathrm{ZrO}_{2}$

Considered as one of the most ambitious goals of the presented studies, the thin film model system preparation is successfully taken to a higher complexity level in establishing a new pathway to model mixed-oxide systems. The novel preparation pathway allows easy structural, spectroscopic and catalytic characterization. Exemplarily discussed for binary $\mathrm{GaO}_{\mathrm{x}} / \mathrm{WO}_{\mathrm{x}}$ [42] and yttria-stabilized $\mathrm{ZrO}_{2}$ thin films, it is shown that this preparation routine also opens up exciting new possibilities to access a full range of oxide combinations relevant in a variety of research areas including catalysis, sensor technology and materials chemistry. Similar to pure oxides, careful tuning of the experimental conditions eventually yields a nanoarchitectured mixed-oxide system. 
Regarding $\mathrm{GaO}_{\mathrm{x}} / \mathrm{WO}_{\mathrm{x}}$, the importance is derived from is catalytic action in methanol synthesis, since the oxide-oxide interface is suspected to govern the catalytic activity and selectivity. The thin film structure and morphology strongly differ from those of the pure oxides, and upon co-deposition of both oxides also leads to the formation of a branched network of Ga-enriched dendrites within a W-enriched binary oxide matrix (Figure 12, TEM and HAADF images A and B). AFM measurements showed that these dendrites only form at the $\mathrm{GaO}_{\mathrm{x}} / \mathrm{NaCl}(001)$ interfacial contact area. Thus, the formation appears to be a surfacerelated phenomenon, rather than an intrinsic property of the mixed-oxide bulk [42].

Due to the inherent difficulties in controlling the stoichiometry of as-prepared mixed oxide systems, for the preparation of yttria-stabilized $\mathrm{ZrO}_{2}$, a slightly different pathway has to be chosen, which, nevertheless exploits the advantages of the $\mathrm{NaCl}(001)$ growth template. As the exact stoichiometry of the thin film is almost impossible to be controlled by simple thermal evaporation, a YSZ film has to be prepared via sputtering onto the $\mathrm{NaCl}$ template, rather than to be deposited by thermal or electron-beam evaporation. Using tetragonal YSZ powder (stabilized by 8 at $\%$ Y) as sputter target, free-standing films of $\sim 25 \mathrm{~nm}$ thickness could be prepared and characterized by electron microscopy and X-ray photoelectron spectroscopy. The SAED inset in Figure 13 reveals that even after deposition at room temperature, a polycrystalline tetragonal YSZ structure is formed [71], which nevertheless in TEM images (large panel) does not show contrast. The left inset shows representative Zr 3d and Y 3d XPS peaks, whose quantitative analysis reveals a film composition (in at $\%$ ) close to that of the sputter target (Zr:Y:O =31:7:62).

\section{Conclusions}

In conclusion, the presented case studies clearly showed that the $\mathrm{NaCl}(001)$ substrate can be beneficial in two ways for obtaining well-defined model systems for oxides: Either it beneficially influences surface and interfacial regions (e.g., $\mathrm{V}_{2} \mathrm{O}_{5}, \mathrm{Ga}_{2} \mathrm{O}_{3}-\mathrm{WO}_{3}, \mathrm{Ga}_{2} \mathrm{O}_{3}, \mathrm{PdO}$, 
$\mathrm{VO}, \mathrm{GeO}_{2}$ ) and/or it successfully exploits structural similarities between the template and the respective oxide species $\left(\mathrm{In}_{2} \mathrm{O}_{3}, \mathrm{PdO}, \mathrm{WO}_{3}, \mathrm{SnO}, \mathrm{SnO}_{2}, \mathrm{~V}_{2} \mathrm{O}_{3}, \mathrm{ZrO}_{2}, \mathrm{Y}_{2} \mathrm{O}_{3}, \mathrm{CuO}, \mathrm{NiO}, \mathrm{CeO}_{2}\right.$, YSZ). The advantages are multifold and encompass:

- usually highly ordered structures and morphologies are obtained

- preparation at comparably low template temperatures, especially for obtaining welldefined particle morphologies

- typically the preparation involves only one-step processes. Only for a few exceptions are oxidation or reduction post-preparation treatments necessary, and they are easy to accomplish.

- large contact area for (inter-)metal-oxide systems, facilitating studies of catalytic adlineation and phase boundary effects.

- structural and spectroscopic characterization are greatly facilitated and can be combined with determination of properties of technological relevance such as catalytic behavior or materials properties under technologically relevant conditions. Thus, structure-activity/selectivity/property relationships can be easily established.

As a closing remark, the tremendous extension possibilities should be mentioned, by far exceeding the rather limited preparation and application examples discussed in this review. Varying the preparation conditions, the possible pathways to similar systems, be it pure oxide, mixed oxides or supported metal/oxide systems are extensive. However, it should be mentioned that most probably, transition metal oxide systems are most rewarding, particularly due to their technological relevance. Most demanding regarding the preparation and characterization are definitely mixed oxide systems, due to the inherent complexity of oxides. Whereas for pure oxides, a more or less defined preparation setup exists (either via thermal or e-beam evaporation), the experimental conditions have to be very carefully adjusted to the special necessities of the particular mixed-oxide system. No set recipe can be given in the 
latter case. However, one of the particular strengths of the outlined preparation approach is the easy access to characterization of multiple oxide phases (distinct polymorphs or different metal oxide structures), which are otherwise only accessible via demanding chemical preparation.

\section{Acknowledgments}

This work has been financially supported by the Austrian Science Fund (FWF) within the projects P20892-N19 and F4503-N16 and has been performed within the framework of the Forschungsplattform Materials- and Nanoscience. The past and present people of the workgroup "Nanostructured Catalysts" at the Institute of Physical Chemistry at the University of Innsbruck are particularly thanked for assistance and support. 


\section{References}

[1] Model Systems in Catalysis: Single Crystals to Supported Enzyme Mimics (R. Rioux, Ed.), Springer, New York, 2010

[2] Synthesis, Properties and Applications of Oxide Nanomaterials, J. A. Rodriguez, Wiley, Weinheim, 2007

[3] D. Freeman, R. P. K. Wells, G. J. Hutchings, Conversion of Methanol to Hydrocarbons over $\mathrm{Ga}_{2} \mathrm{O}_{3} / \mathrm{H}-\mathrm{ZSM}-5$ and $\mathrm{Ga}_{2} \mathrm{O}_{3} / \mathrm{WO}_{3}$ catalysts, J. Catal. 205 (2002) 358-365

[4] I. E. Wachs, Recent conceptual advances in the catalysis science of mixed metal oxide catalytic materials, Catal. Today 100 (205) 79-94 and references therein

[5] J. M. Lopez-Nieto, P. Botella, B. Solsona, J. M. Oliver, The selective oxidation of propane on Mo-V-Te-Nb-O catalysts: The influence of Te-precursor, Catal. Today 81 (2003) $87-94$

[6] J. M. Lopez-Nieto, P. Botella, M. I. Vazquez, A. Dejoz, The selective oxidative dehydrogenation of ethane over hydrothermally synthesised MoVTeNb catalysts, Chem. Commun. (2002) 1906-1907

[7] S. H. Taylor, J.S.J. Hargreaves, G. J. Hutchings, R. W. Joyner, C. W. Lembacher, The partial oxidation of methane to methanol: An approach to catalyst design, Catal. Today 42 (1998) 217-224

[8] H.-J. Freund, H. Kuhlenbeck, J. Libuda, G. Rupprechter, M. Bäumer, H. Hamann, Bridging the pressure and materials gaps between catalysis and surface science: clean and modified oxide surfaces, Top. Catal. 15 (2001) 201-209 
[9] G. Rupprechter, A surface science approach to ambient pressure catalytic reactions Catal. Today $126(2007) 3-17$

[10] G. A. Somorjai, The Flexible Surface. Correlation between Reactivity and Restructuring Ability, Langmuir 7 (1991) 3176-3182

[11] K. Hayek, M. Fuchs, B. Klötzer, W. Reichl, G. Rupprechter, Studies of metal-support interactions with „real“ and ,inverted“ model systems: reactions of $\mathrm{CO}$ and small hydrocarbons with hydrogen on noble metals in contact with oxides, Top. Catal. 13 (2000) $55-66$

[12] H.-J. Freund, Adsorption of Gases on Complex Solid Surfaces, Angew. Chemie Intl. Ed. 36 (1997) 452-475

[13] C. T. Campbell, Ultrathin metal films and particles on oxide surfaces: structural, electronic and chemisorptive properties, Surf. Sci. Rep. 27 (1997) 1-111

[14] C. R. Henry, Surface studies of supported model catalysts, Surf. Sci. Rep. 31 (1998) $231-233,235-325$

[15] G. Rupprechter, Surface vibrational spectroscopy on noble metal catalysts from ultrahigh vacuum to atmospheric pressure, Annu. Rep. Progr. Chem. Sect. C 100 (2004) 237311

[16] S. M. Davis, F. Zaera, G. A. Somorjai, Surface structure and temperature dependence of light-alkane skeletal rearrangement reactions catalyzed over platinum single-crystal surfaces, J. Am. Chem. Soc. 104 (1982) 7453-7461

[17] W. Reichl, G. Rosina, G. Rupprechter, C. Zimmermann, K. Hayek, Ultrahigh vacuum compatible all-glass high pressure reaction cell for accurate and reproducible measurement of small reaction rates, Rev. Sci. Instrum. 71 (2000) 1495-1499 
[18] G. Rupprechter, T. Dellwig, H. Unterhalt, H.-J. Freund, CO adsorption on Ni(100) and $\operatorname{Pt}(111)$ studied by infrared-visible sum frequency generation spectroscopy: design and application of an SFG-compatible UHV-high-pressure reaction cell, Top. Catal. 15 (2001) 1926

[19] D. Ogletree, H. Bluhm, G. Lebedev, C. Fadley, Z. Hussain, M. Salmeron, A differentially pumped electrostatic lens system for photoemission studies in the millibar range, Rev. Sci. Instrum. 73 (2002) 3872-3877

[20] H. Bluhm, M. Hävecker, E. Kleimenov, A. Knop-Gericke, A. Lisowski, D. S. Su, R. Schlögl, In Situ Surface Analysis in Selective Oxidation Catalysis: n-Butane Conversion Over VPP, Top. Catal. 23 (2003) 99-107

[21] V. V. Kaichev, I.P. Prosvirin, V. I. Bukhtiyarov, H. Unterhalt, G. Rupprechter, H.-J. Freund, High-pressure studies of $\mathrm{CO}$ adsorption on $\mathrm{Pd}(111)$ by $\mathrm{X}$-ray photoelectron spectroscopy and sum-frequency generation, J. Phys. Chem. B 107 (2003) 3522-3527

[22] E. Laegsgaard, L. Österlund, P. Thostrup, P. B. Rasmussen, I. Stensgaard, F. Besenbacher, A high-pressure scanning tunneling microscope, Rev. Sci. Instr. 72 (2001) $3537-3542$

[23] D. W. Pashley, The study of epitaxy in thin surface films, Adv. Phys. 5 (1956) 173240

[24] J. W. Matthews, Growth of face-centered cubic metals on sodium chloride substrates, J. Vac. Sci. Technol. 3 (1966) 133-145

[25] L. E. Murr, Effects of substrate temperature, pressure, and high evaporation rates on nucleation, epitaxy, and structure of palladium thin films, Thin Solid Films 7 (1971) 101-115 
[26] C. Chapon, C. R. Henry, A. Chemam, Formation and characterization of small Pd particles deposited on $\mathrm{MgO}$ as a model catalyst, Surf. Sci. 162 (1985) 747-754

[27] H. Hofmeister, H. Haefke, A. Panov, Habit of gold particles vapour-deposited onto silver bromide films, J. Cryst. Growth 58 (1982) 507-516

[28] R. Conrad, M. Harsdorff, Nucleation and growth of thin gold films on $\mathrm{NaCl}(100)$ cleavage planes under carefully controlled conditions, Thin Solid Films 192 (1990) 163-171

[29] E. Grünbaum, in J. W. Matthews (Ed.), Epitaxial Growth, Academic Press 1975, Part B, p. 611

[30] G. Rupprechter, K. Hayek, H. Hofmeister, Electron Microscopy of Thin-Film Model Catalysts: Activation of Alumina-Supported Rhodium Nanoparticles, J. Catal. 173 (1998) $409-422$

[31] G. Rupprechter, G. Seeber, K. Hayek, H. Hofmeister, Epitaxial noble metal particles upon oxidation and reduction. A model system for supported metal catalysts, Physica Status Solidi (a) 146 (1994) 449-459

[32] S. Penner, B. Klötzer, B. Jenewein, X. Liu, E. Bertel, F. Klauser, Growth and stability of $\mathrm{Ga}_{2} \mathrm{O}_{3}$ nanospheres, Thin Solid Films 516 (2008) 4742-4749

[33] H. Lorenz, M. Stöger-Pollach, S. Schwarz, J. Bernardi, Ch. Pfaller, B. Klötzer, S. Penner, A New Preparation Pathway to Well-Defined $\operatorname{In}_{2} \mathrm{O}_{3}$ Nanoparticles at Low Substrate Temperatures, J. Phys. Chem. C 112 (2008) 918-925

[34] S. Penner, B. Jenewein, H. Gabasch, B. Klötzer, D. Wang, A. Knop-Gericke, R. Schlögl, K. Hayek, Growth and structural stability of well-ordered PdZn alloy nanoparticles, J. Catal. 241 (2006) 14-19 
[35] S. Penner, B. Klötzer, B. Jenewein, X. Liu, F. Klauser, E. Bertel, The structure and composition of oxidized and reduced tungsten oxide thin films, Thin Solid Films 516 (2008) $2829-2836$

[36] S. Penner, D. Wang, R. Schlögl, K. Hayek, Rhodium particles supported by thin vanadia films as model systems for catalysis: An electron microscopy study, Thin Solid Films $484(2005) 10-17$

[37] R. Thalinger, M. Stöger-Pollach, B. Klötzer, S. Penner, Thin film model systems of $\mathrm{ZrO}_{2}$ and $\mathrm{Y}_{2} \mathrm{O}_{3}$ as templates for potential industrial applications investigated by means of electron microscopy, Mater. Chem. Phys. 138 (2013) 384-391

[38] H. Lorenz, Q. Zhao, O. Lebedev, S. Turner, G. van Tendeloo, C. Rameshan, B.Klötzer, S. Penner, Preparation and structural characterization of $\mathrm{SnO}_{2}$ and $\mathrm{GeO}_{2}$ methanol steam reforming thin film model catalysts by (HR)TEM, Mater. Chem. Phys. 122 (2010) 623629

[39] Q. Zhao, H. Lorenz, O. Lebedev, St. Turner, G. van Tendeloo, C. Rameshan, B.

Klötzer, J. Konzett, S. Penner, Catalytic characterization of pure $\mathrm{SnO}_{2}$ and $\mathrm{GeO}_{2}$ in methanol steam reforming, Appl. Catal. A 375 (2010) 188-195

[40] L. Mayr, N. Köpfle, A. Auer, B. Klötzer, S. Penner, An (ultra) high-vacuum compatible sputter source for oxide thin film growth, Rev. Sci. Instr. 84 (2013) 094103-1 094103-9

[41] S. Penner, B. Jenewein, H. Gabasch, B. Klötzer, D. Wang, A. Knop-Gericke, R. Schlögl, K. Hayek, Growth and decomposition of aligned and ordered PdO nanoparticles, J. Chem. Phys. 125 (2006) 094703-1 - 194703-7 
[42] S. Penner, M. Stöger-Pollach, F. Klauser, H. Lorenz, B. Klötzer, X. Liu, B. Jenewein, E. Bertel, Dendritic growth of amorphous gallium oxide in mixed $\mathrm{GaO}_{\mathrm{x}} / \mathrm{WO}_{\mathrm{x}}$ thin films, Mater. Chem. Phys. 116 (2009) 175-182

[43] D. Wang, S. Penner, D. S. Su, G. Rupprechter, K. Hayek, R. Schlögl, Silicide formation on a Pt/SiO 2 model catalyst studied by TEM, EELS, and EDXS, J. Catal. 219 (2003) 434-441

[44] S. Penner, H. Lorenz, B. Klötzer, D. Wang, M. Stöger-Pollach, C. Rameshan, W. Jochum, $\mathrm{Pd} / \mathrm{Ga}_{2} \mathrm{O}_{3}$ methanol steam reforming catalysts: Part I. Morphology, composition and structural aspects, Appl. Catal. A 358 (2009) 193-202

[45] S. Penner, B. Jenewein, D. Wang, R. Schlögl and K. Hayek, Structure-activity correlations in thin film model catalysts: $\mathrm{CO}$ hydrogenation on $\mathrm{Rh} / \mathrm{VO}_{\mathrm{x}}$ : Part I. The morphology, composition and structure of vanadia-supported and -promoted Rh particles upon oxidation and reduction, Appl. Catal. A 308 (2006) 31-42

[46] A. Trovarelli (Ed.), Catalysis by Ceria and Related Materials, Imperial College Press, London, 2002, Catalytic Series Vol.2

[47] S. Penner, D. Wang, R. Podloucky, R. Schlögl, K. Hayek, Rh and Pt nanoparticles supported by $\mathrm{CeO}_{2}$ : Metal-support interaction upon high-temperature reduction observed by electron microscopy, Phys.Chem.Chem.Phys. 6 (2004) 5244-5249

[48] S. Penner, phD-Thesis, University of Innsbruck 2003

[49] S. Penner, B. Klötzer, B. Jenewein, Structural and redox properties of $\mathrm{VO}_{\mathrm{x}}$ and $\mathrm{Pd} / \mathrm{VO}_{\mathrm{x}}$ thin film model catalysts studied by TEM and SAED, Phys.Chem.Chem.Phys. 6 (2004) 2428-2433 
[50] H. Lorenz, M. Stöger-Pollach, S. Schwarz, J. Bernardi, K. Pfaller, B. Klötzer, S. Penner, Novel methanol steam reforming activity and selectivity of pure $\operatorname{In}_{2} \mathrm{O}_{3}$, Appl. Catal. A 347 (2008) 34-42

[51] J. A. Rodriguez, J. C. Hanson, A. I. Frenkel, A.-Y. Kim, M. Perez, Experimental and Theoretical Studies on the Reaction of $\mathrm{H}_{2}$ with NiO: Role of $\mathrm{O}$ Vacancies and Mechanism for Oxide Reduction, J. Amer. Chem. Soc. 124 (2002) 346-354 and references therein

[52] E. Bontempi, E. Zampiceni, G. Sberveglieri, L. E. Depero, Structural Characterization of Tin and Molybdenum Oxides Thin Films Deposited by RGTO, Chem. Mater. 13 (2001) $2608-2612$

[53] H. J. Chun, Y. S. Choi, S. Y. Bae, J. Park, Bicrystalline indium oxide nanobelts, J. Appl. Phys. A 81 (2005) 539-542

[54] J. G. Railsback, A. C. Johnston-Peck, J. Wang, J. B. Tracy, Size-Dependent Nanoscale Kirkendall Effect During the Oxidation of Nickel Nanoparticles, ACS Nano 4 (2010) 1913 and references therein; Wang, W.; Dahl, M.; Yin, Y. Hollow nanocrystals through the nanoscale Kirkendall effect, Chem. Mat. 25(8) (2013) 1179-1189

[55] M. Rühle, Microscopy of Structural Ceramics, Adv. Mater. 9 (1997) 195-217 and references therein

[56] M. Batzill, U.Diebold, The Surface Science of Tin oxide, Prog. Surf. Sci. 79 (2005) $47-154$

[57] D. S. Su, M. Wieske, E. Beckmann, A. Blume, G. Mestl, R. Schlögl, Electron beam induced reduction of $\mathrm{V}_{2} \mathrm{O}_{5}$ studied by analytical electron microscopy, Catal. Lett. 13 (2001) $81-86$ 
[58] J. A. Rodriguez, J. Y. Kim, J. C. Hanson, M. Perez, A. I. Frenkel, Reduction of CuO in $\mathrm{H}_{2}$ : in-situ time-resolved XRD studies, Catal. Lett. 85 (2003) 247-254

[59] R. Thalinger, M. Heggen, D. G. Stroppa, M. Stöger-Pollach, B. Klötzer, S. Penner, Formation and stability of small well-defined $\mathrm{Cu}$ - and Ni oxide particles, Mater. Chem. Phys 143 (2013) 184-194

[60] H. Lorenz, S. Penner, B. Klötzer, C. Rameshan, W.Jochum, $\mathrm{Pd} / \mathrm{Ga}_{2} \mathrm{O}_{3}$ methanol steam reforming catalysts: Part II. Catalytic selectivity, Appl. Catal. A 358 (2009) 203-210

[61] T. Bielz, H. Lorenz, P. Amann, B. Klötzer, S. Penner, Water-Gas Shift and Formaldehyde Reforming Activity Determined by Defect Chemistry of Polycrystalline $\operatorname{In}_{2} \mathrm{O}_{3}$, J. Phys. Chem. C 115 (2011) 6622-6628

[62] W. Jochum, S. Penner, R. Kramer, B. Klötzer, K. Föttinger, G. Rupprechter, Defect formation and the water-gas shift reaction on $\beta-\mathrm{Ga}_{2} \mathrm{O}_{3}$, J. Catal. 256 (2008) 278-286

[63] J. M. Tatibouet, Methanol oxidation as a catalytic surface probe, Appl. Catal. A 148 (1997) 213-252

[64] S. J. Tauster, S. C. Fung, R. L. Garten, Strong metal-support interactions. Group 8 noble metals supported on titanium dioxide, J. Am. Chem. Soc. 100 (1978) 170-175

[65] S. Bernal, J. J. Calvino, M. A. Cauqui, J. M. Gatica, C. López Cartes, J. A. Pérez Omil, J. M. Pintado, Some contributions of electron microscopy to the characterisation of the strong metal-support interaction effects, Catal. Today 77 (2003) 385-406

[66] R. Burch, Strong metal-support interactions, in Hydrogen Effects in Catalysis, Z. Paal and P. G. Menon, Eds., Marcel Dekker, New York (1988) 
[67] M. Armbrüster, Intermetallic Compounds in Catalysis, in Encyclopedia of Catalysis, Wiley, 2011, Weinheim

[68] B. Jenewein, S. Penner, D. Wang, R. Schlögl and K. Hayek, Structure-activity correlation in thin film model catalysts: $\mathrm{CO}$ hydrogenation on $\mathrm{Rh} / \mathrm{VO}_{\mathrm{x}}$ : Part II. Catalytic activity as a function of oxidation and reduction, Appl. Catal. A 308 (2006) 43-49

[69] S. Penner, D. Wang, D. S. Su, G. Rupprechter, R. Podloucky, R. Schlögl, K. Hayek, Platinum nanocrystals supported by silica, alumina and ceria: metal-support interaction due to high-temperature reduction in hydrogen, Surf. Sci. 532-535 (2003) 276-280

[70] N. Iwasa, N. Takezawa, New supported Pd and Pt alloy catalysts for steam reforming and dehydrogenation of methanol, Top. Catal. 22 (2003) 215-224

[71] M. Yashima, S. Sasaki, M. Kakihana, Y. Yamaguchi, H. Arashi, M. Yoshimura, Oxygen-induced structural change of the tetragonal phase around the tetragonal-cubic phase boundary in $\mathrm{ZrO}_{2}-\mathrm{YO}_{1.5}$ solid solutions, Acta Cryst. B 50 (1994) 663-672 


\section{Figure Captions}

Figure 1: Overview of the preparation process of oxide thin films for structural and catalytic characterization. Adapted from [1]. Copyright 2010 Springer.

Figure 2: Case study 1: Preparation of well-structured and-defined oxide phases and their stability under reducing conditions. Panels (A) and (B) show TEM images of the as-grown states of (A) face-centered cubic $\mathrm{CeO}_{2}$ and (B) body-centered cubic $\mathrm{Y}_{2} \mathrm{O}_{3}$. Corresponding SAED patterns are shown as insets. Images (C) and (D) show the structure and composition of the same films after a reduction treatment at $1073 \mathrm{~K}$ in hydrogen. Corresponding SAED patterns are shown as insets. The left inset in (C) shows a high-resolution TEM image of a sub-stoichiometric $\mathrm{CeO}_{2-x}$ phase. Important reflections in the SAED patterns have been labeled. Adapted partially from references [37,46]. Copyright 2013 Elsevier.

Figure 3: Case study 2: Preparation of oxide nanoarchitectures. (A): TEM image of $\operatorname{In}_{2} \mathrm{O}_{3}$ nano-pyramidal particles with bcc-structure grown at $573 \mathrm{~K}$. Corresponding SAED pattern shown in the right inset. Left inset: TEM image of a nanostructured $\mathrm{Pd} / \mathrm{In}_{2} \mathrm{O}_{3}$ entity. (B): TEM image of amorphous nanospherical $\mathrm{Ga}_{2} \mathrm{O}_{3}$ particles. The SAED pattern is shown in the right inset; the left inset represents an AFM-image of the spherical particles. (C): TEM image of oblong and needle-like $\mathrm{V}_{2} \mathrm{O}_{5}$ aggregates. An SAED pattern is shown in the right inset. Left inset: TEM image of a nanostructured $\mathrm{Pd} / \mathrm{V}_{2} \mathrm{O}_{5}$ needle-like aggregate. (D): HAADF image of porous $\mathrm{NiO}$ particles with SAED pattern and EELS spectra shown in the right and left insets, respectively. For comparison, an EELS spectrum of Ni metal is also shown. Adapted partially from references [32,33,48]. Copyright 2008 American Chemical Society, 2008 and 2013 Elsevier and 2007 Royal Chemical Society.

Figure 4: Case study 3: Structural transformations between different oxide polymorphs: (A), (B) and (C) show TEM images of the structural evolution of $\mathrm{WO}_{3}$ from (A) amorphous $\rightarrow$ (B) 
$\mathrm{WO}_{3}$ monoclinic $\rightarrow(\mathrm{C}) \mathrm{WO}_{3}$ hexagonal. $\mathrm{WO}_{3}$ was deposited at $573 \mathrm{~K}$, exhibiting an amorphous SAED pattern (right inset in (A)) and W 4f XPS peaks typical of $\mathrm{WO}_{3}$ (left inset in (A)). TEM image in (B) acquired after oxidation at $673 \mathrm{~K}$ in air, TEM image in (C) after oxidation at $773 \mathrm{~K}$. Insets show the respective SAED patterns and (B) high-resolution details of a strained $\mathrm{WO}_{3}$ particle and (C) $\mathrm{WO}_{3}(100)$ lattice planes. Copyright 2008 Elsevier. (D), (E) and (F) highlight TEM images of the structural evolution and phase transformation of $\mathrm{ZrO}_{2}$ : (D) amorphous $\rightarrow$ (E) $\mathrm{ZrO}_{2}$ tetragonal $\rightarrow(\mathrm{F}) \mathrm{ZrO}_{2}$ monoclinic. Image (D) obtained after deposition at $300 \mathrm{~K}$, image (E) after annealing at $673 \mathrm{~K}$ and image (F) after annealing at $873 \mathrm{~K}$. SAED patterns shown as insets, important reflections of the tetragonal $\mathrm{ZrO}_{2}$ structure have been labeled in (E). Adapted partially from reference [35,37]. Copyright 2013 Elsevier.

Figure 5: Case study 4: Structural transformation between different oxide structures I. The system $\mathrm{SnO} / \mathrm{SnO}_{2}$. (A) and (B) show TEM images of $\mathrm{SnO}$ (prepared at $573 \mathrm{~K}$ in $10^{-3}$ mbar $\mathrm{O}_{2}$ ) and $\mathrm{SnO}_{2}$ (after post-oxidation of the film shown in panel (A) at $673 \mathrm{~K}$ ) phases, respectively. The SAED pattern (right inset in (A)) confirms the presence of single-crystalline $\mathrm{SnO}$, the left inset shows a high-resolution detail of $\mathrm{SnO}(111)$ lattice spacings. The inset in panel (B) highlights an overview of EELS O K-edges, acquired on respective thin film samples, typical for $\beta$-Sn metal, $\mathrm{SnO}$ and $\mathrm{SnO}_{2}$. Adapted partially from reference [38]. Copyright 2010 Elsevier.

Figure 6: Case study 4: Structural transformation between different oxide structures II. The system $\mathrm{V}_{2} \mathrm{O}_{3} / \mathrm{V}_{2} \mathrm{O}_{5} / \mathrm{VO}$. (A): $\mathrm{V}_{2} \mathrm{O}_{3}$ thin film, prepared at $573 \mathrm{~K}$ in $10^{-4}$ mbar $\mathrm{O}_{2}$, (B): $\mathrm{V}_{2} \mathrm{O}_{5}$ thin film, obtained after further oxidation at $673 \mathrm{~K},(\mathrm{C})$ : VO thin film, obtained after subsequent reduction at $673 \mathrm{~K}$. Corresponding SAED patterns are shown in the insets, important reflections of the respective orthorhombic $\mathrm{V}_{2} \mathrm{O}_{3}$, monoclinic $\mathrm{V}_{2} \mathrm{O}_{5}$ and cubic $\mathrm{VO}$ structures have been labeled. Adapted partially from reference [36]. Copyright 2008 Elsevier. 
Figure 7: Case study 5: Use of model systems for catalytic studies $\mathrm{I}: \operatorname{In}_{2} \mathrm{O}_{3}$. Upper panel: $\mathrm{In}_{2} \mathrm{O}_{3}$ thin film grown on a polycrystalline $\mathrm{NaCl}$ film at $573 \mathrm{~K}$. The corresponding SAED pattern (shown in the right inset) confirms the presence of bcc- $\operatorname{In}_{2} \mathrm{O}_{3}$, the left inset shows representative EELS O K- and In $\mathrm{M}_{4,5}$-spectra, typical for an $\operatorname{In}_{2} \mathrm{O}_{3}$ stoichiometry.

Bottom panel: Catalytic activity of the $\mathrm{In}_{2} \mathrm{O}_{3}$ thin film sample in methanol steam reforming $\mathrm{CH}_{3} \mathrm{OH}+\mathrm{H}_{2} \mathrm{O} \rightleftharpoons \mathrm{CO}_{2}+3 \mathrm{H}_{2}$ (left) in comparison with conventional $\mathrm{In}_{2} \mathrm{O}_{3}$ powder (right). Adapted partially from reference [33, 49]. Copyright 2008 Elsevier and 2008 American Chemical Society.

Figure 8: Case study 5: Use of model systems for catalytic studies II: $\mathrm{Ga}_{2} \mathrm{O}_{3}$. The main panel highlights the catalytic activity of a $\mathrm{Ga}_{2} \mathrm{O}_{3}$ thin film (grown on a polycrystalline $\mathrm{NaCl}$ film at $573 \mathrm{~K}$ ) in the methanol steam reforming reaction $\mathrm{CH}_{3} \mathrm{OH}+\mathrm{H}_{2} \mathrm{O} \rightleftharpoons \mathrm{CO}_{2}+3 \mathrm{H}_{2}$. " $\mathrm{CO}_{2}$ ", "CO" and "HCOOH" indicate the products formed in the MSR reaction (using the same colors as the corresponding mass spectrometer traces). In the insets, a TEM image of the structure of the catalyst (top), as well as a set of XPS spectra of the $\mathrm{Ga}_{2} \mathrm{O}_{3}$ thin film taken after different catalytic activation treatments, basically confirming the $\mathrm{Ga}_{2} \mathrm{O}_{3}$ stoichiometry (bottom), are shown. Adapted partially from references [32,59]. 2008 Elsevier.

Figure 9: Case study 6: Studies on the strong metal-support interaction-reduction formation of oxide-supported intermetallic phases I: $\mathrm{Pt} / \mathrm{SiO}_{2}$. (A): TEM image of the $\mathrm{Pt} / \mathrm{SiO}_{2}$ thin film catalyst in the as-grown state. SAED pattern shown in the inset, some of the fcc Pt spots have been labeled. (B): TEM image of the thin film after reduction in hydrogen at $873 \mathrm{~K}$. Corresponding SAED pattern are shown in the inset. Some of the fcc Pt spots have been indexed, some spots of the $\mathrm{Pt}_{3} \mathrm{Si}$ intermetallic phase labeled by arrows. The corresponding left insets in both panels show HRTEM images of single metal Pt and intermetallic $\mathrm{Pt}_{3} \mathrm{Si}$ particles, exhibiting $\mathrm{Pt}(200)$ and $\mathrm{Pt}_{3} \mathrm{Si}(100)$ lattice fringes. Adapted partially from reference [42]. Copyright 2003 Elsevier. 
Figure 10: Case study 6: Studies on the strong metal-support interaction-reduction formation of oxide-supported intermetallic phases II: $\mathrm{Pd} / \mathrm{Ga}_{2} \mathrm{O}_{3}$. (A): TEM image of the $\mathrm{Pd} / \mathrm{Ga}_{2} \mathrm{O}_{3}$ thin film catalyst in the as-grown state. Corresponding SAED pattern is shown in the inset, some of the fcc Pd spots have been labeled. (B): TEM image of sintered former Pd particles after reduction at $673 \mathrm{~K}$, now in the partially intermetallic $\mathrm{Pd}_{5} \mathrm{Ga}_{2}$ state. The corresponding SAED pattern is shown in the inset, some spots of the orthorhombic $\mathrm{Pd}_{5} \mathrm{Ga}_{2}$ structure have been labeled. (C): TEM image of the $\mathrm{Pd} / \mathrm{Ga}_{2} \mathrm{O}_{3}$ catalyst after an reduction-oxidation cycle at $523 \mathrm{~K}$ and $673 \mathrm{~K}$, respectively. The corresponding SAED patterns (inset) show a mixture of PdO and Pd. (D): TEM image of the $\mathrm{Pd} / \mathrm{Ga}_{2} \mathrm{O}_{3}$ catalyst after a reduction-oxidation cycle at $673 \mathrm{~K}$ and $673 \mathrm{~K}$, respectively. The corresponding SAED pattern is shown in the inset and some of the fcc Pd spots have been labeled. Adapted partially from reference [43]. Copyright 2009 Elsevier.

Figure 11: Case study 6: Studies on the strong metal-support interaction-reductive formation of oxide-supported intermetallic phases III: $\mathrm{Rh} / \mathrm{VO}_{\mathrm{x}}$. Upper panel: Catalytic activity and selectivity of the $\mathrm{Rh} / \mathrm{VO}_{\mathrm{x}}$ thin film in CO hydrogenation $n C O+(3 n+1) H_{2} \rightleftharpoons C_{n} H_{2 n+2}+$ $\mathrm{H}_{2} \mathrm{O}$ (alkane formation) and $\mathrm{nCO}+3 n \mathrm{H}_{2} \rightleftharpoons \mathrm{C}_{n} \mathrm{H}_{2 n}+n \mathrm{H}_{2} \mathrm{O}$ (alkene formation) after different reduction and oxidation treatments, as indicated. The respective selectivity patterns are shown in the insets. Bottom panel: TEM images and SAED patterns of the structure of the $\mathrm{Rh} / \mathrm{VO}_{\mathrm{x}}$ catalysts after selected treatments, indexed by $\mathrm{A}, \mathrm{B}, \mathrm{C}$ and $\mathrm{D}$. Adapted partially from reference [44,67]. Copyright 2006 Elsevier.

Figure 12: Case study 7: Preparation and characterization of mixed oxide systems I: $\mathrm{Ga}_{2} \mathrm{O}_{3^{-}}$ $\mathrm{WO}_{3}$. (A): TEM image and SAED pattern of $\mathrm{Ga}_{2} \mathrm{O}_{3}$ dendrites within the $\mathrm{WO}_{3}$ matrix, prepared by co-deposition at $573 \mathrm{~K}$. (B): HAADF image of the same structure alongside an EDX line profile, confirming the preferential presence of Ga within the dendrites. The Index 
" 1 " is used to better indicate the line profile. Adapted from reference [41]. Copyright 2010 Elsevier

Figure 13: Case study 7: Preparation and characterization of mixed oxide systems II: $\mathrm{Y}_{2} \mathrm{O}_{3}$ stabilized $\mathrm{ZrO}_{2}$. TEM image of a crystalline YSZ film deposited by sputtering from an 8 at\%YSZ target onto $\mathrm{NaCl}(001)$. Template temperature: $300 \mathrm{~K}$. The corresponding SAED pattern is shown in the right inset and important reflections of the YSZ structure have been labeled. On the left, representative Y 3d and Zr 3d XPS peaks are shown, yielding a quantitative ratio of O:Zr:Y=62:31:7 (at\%). Copyright 2013 Elsevier. 


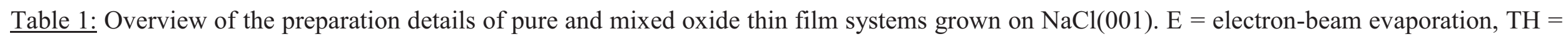
thermal evaporation, $x$ = value not applicable, evaporation crucible (either Ta, W, Mo or Ti) stated after "E” or "TH".

\begin{tabular}{|c|c|c|c|c|c|c|c|c|}
\hline & Oxide & Structure & Morphology & $\begin{array}{c}\text { Substrate } \\
\text { Temperature / } \mathrm{K}\end{array}$ & Method & Source & $\begin{array}{l}\text { Pressure } \\
\text { / mbar }\end{array}$ & Notes \\
\hline \multicolumn{9}{|l|}{ Pure Oxides } \\
\hline \multirow[t]{5}{*}{ 3rd group } & $\mathrm{Al}_{2} \mathrm{O}_{3}[1]$ & amorphous & $\mathrm{x}$ & $300-573$ & $\mathrm{E} / \mathrm{Ta}$ & Al metal & $10^{-4} \mathrm{O}_{2}$ & crystallizes to $\mathrm{\gamma}-\mathrm{Al}_{2} \mathrm{O}_{3}$ upon heating in e-beam \\
\hline & $\mathrm{Ga}_{2} \mathrm{O}_{3}[32]$ & amorphous & $x$ & 300 & $\mathrm{TH} / \mathrm{Ta}$ & $\beta-\mathrm{Ga}_{2} \mathrm{O}_{3}$ & $10^{-4} \mathrm{O}_{2}$ & W contamination if $W$ crucible is used \\
\hline & $\mathrm{Ga}_{2} \mathrm{O}_{3}[32]$ & amorphous & spherical & 573 & $\mathrm{TH} / \mathrm{Ta}$ & $\beta-\mathrm{Ga}_{2} \mathrm{O}_{3}$ & $10^{-4} \mathrm{O}_{2}$ & $\mathrm{x}$ \\
\hline & $\ln _{2} \mathrm{O}_{3}[33]$ & polycryst & $\mathrm{x}$ & 300 & $\mathrm{TH} / \mathrm{Ta}$ & bcc- $-\ln _{2} \mathrm{O}_{3}$ & $10^{-4} \mathrm{O}_{2}$ & $\mathrm{x}$ \\
\hline & $\ln _{2} \mathrm{O}_{3}[33]$ & single-cryst & pyramidal & 573 & $\mathrm{TH} / \mathrm{Ta}$ & $\mathrm{bcc}-\ln _{2} \mathrm{O}_{3}$ & $10^{-4} \mathrm{O}_{2}$ & $x$ \\
\hline \multirow[t]{4}{*}{ 4th group } & $\mathrm{SiO}_{2}[34]$ & amorphous & $\mathrm{x}$ & $300-573$ & $\mathrm{TH} / \mathrm{Mo}$ & $\mathrm{SiO}$ & $10^{-4} \mathrm{O}_{2}$ & $x$ \\
\hline & $\mathrm{GeO}_{2}[38]$ & amorphous & $\mathrm{x}$ & $300-573$ & $\mathrm{TH} / \mathrm{Ta}$ & hex- $\mathrm{GeO}_{2}$ & $10^{-4} \mathrm{O}_{2}$ & $\mathrm{x}$ \\
\hline & SnO [38] & single-cryst & $\mathrm{x}$ & 573 & $\mathrm{TH} / \mathrm{Ta}$ & $\mathrm{SnO}_{2}$ & $10^{-3} \mathrm{O}_{2}$ & $\begin{array}{c}\text { high } \mathrm{O}_{2} \text { partial pressure necessary to avoid formation of } \\
\text { metallic } \mathrm{Sn}\end{array}$ \\
\hline & $\mathrm{SnO}_{2}[38]$ & single-cryst & $\mathrm{x}$ & 573 & $\mathrm{TH} / \mathrm{Ta}$ & $\mathrm{SnO}_{2}$ & $10^{-3} \mathrm{O}_{2}$ & post oxidation at $673 \mathrm{~K}$ in air necessary \\
\hline \multirow[t]{12}{*}{$\begin{array}{c}\text { Transition } \\
\text { Metal oxides }\end{array}$} & $\mathrm{Y}_{2} \mathrm{O}_{3}[37]$ & single-cryst & elongated & 573 & $\mathrm{TH} / \mathrm{Ta}$ & Y metal & $10^{-4} \mathrm{O}_{2}$ & \\
\hline & $\mathrm{TiO}_{2}[1]$ & polycryst & $\mathrm{x}$ & $300-573$ & $\mathrm{E} / \mathrm{Ti}$ & Ti metal & $10^{-4} \mathrm{O}_{2}$ & anatase modification \\
\hline & $\mathrm{ZrO}_{2}[37]$ & amorphous & $\mathrm{x}$ & 300 & $\mathrm{TH} / \mathrm{Ta}$ & mono-ZrO ${ }_{2}$ & $10^{-5} \mathrm{H}_{2}$ & hydrogen necessary for suppression of $\mathrm{WO}_{\mathrm{x}}$ formation \\
\hline & $\mathrm{ZrO}_{2}[37]$ & tetragonal & $\mathrm{x}$ & 573 & $\mathrm{TH} / \mathrm{Ta}$ & mono- $-\mathrm{rO}_{2}$ & $10^{-5} \mathrm{H}_{2}$ & hydrogen necessary for suppression of $\mathrm{WO}_{\mathrm{x}}$ formation \\
\hline & $\mathrm{ZrO}_{2}$ & monoclinic & $\mathrm{x}$ & $300 / 573$ & $\mathrm{TH} / \mathrm{Ta}$ & mono-ZrO & $10^{-5} \mathrm{H}_{2}$ & post annealing at $\mathrm{T}>773 \mathrm{~K}$ necessary \\
\hline & $\mathrm{V}_{2} \mathrm{O}_{3}[36]$ & single-cryst & $x$ & 573 & $\mathrm{TH} / \mathrm{Ta}$ & $\mathrm{V}$ metal & $10^{-4} \mathrm{O}_{2}$ & $\begin{array}{l}\text { high } \mathrm{O}_{2} \text { partial pressure necessary to avoid formation of } \\
\text { metallic } \mathrm{Sn}\end{array}$ \\
\hline & $\mathrm{V}_{2} \mathrm{O}_{5}[36]$ & polycryst & plates & 573 & $\mathrm{TH} / \mathrm{Ta}$ & V metal & $10^{-4} \mathrm{O}_{2}$ & post oxidation at $\mathrm{T}=673 \mathrm{~K}$ necessary \\
\hline & $\mathrm{V}_{2} \mathrm{O}_{5}[36]$ & polycryst & needles & 573 & $\mathrm{TH} / \mathrm{Ta}$ & V metal & $10^{-4} \mathrm{O}_{2}$ & post oxidation at $T \geq 773 \mathrm{~K}$ necessary \\
\hline & Vo [36] & polycryst & porous & 573 & $\mathrm{TH} / \mathrm{Ta}$ & $\checkmark$ metal & $10^{-4} \mathrm{O}_{2}$ & post reduction at $\mathrm{T}=673 \mathrm{~K}$ necessary \\
\hline & $\mathrm{WO}_{3}[35]$ & amorphous & $\mathrm{x}$ & $300-573$ & $\mathrm{TH} / \mathrm{W}$ & $\mathrm{WO}_{3}$ & $10^{-4} \mathrm{O}_{2}$ & forms a mixture of crystalline $\mathrm{WO}_{3}$ phases upon oxidation \\
\hline & $\mathrm{NiO}[56]$ & single-cryst & porous & 573 & $\mathrm{E} / \mathrm{W}$ & Ni metal & $x$ & $\begin{array}{c}\text { postoxidation at } \mathrm{T} \geq 473 \mathrm{~K} \text { necessary; susceptible to } \\
\text { Kirkendall effect }\end{array}$ \\
\hline & $\mathrm{PdO}[40]$ & single-cryst & $\mathrm{x}$ & 573 & $E / W$ & Pd metal & $\mathrm{x}$ & post oxidation at $T=673 \mathrm{~K}$ necessary \\
\hline
\end{tabular}




\begin{tabular}{|c|c|c|c|c|c|c|c|c|}
\hline & $\mathrm{CuO}[56]$ & single-cryst & $\mathrm{x}$ & 573 & $\mathrm{E} / \mathrm{W}$ & $\mathrm{Cu}$ metal & $\mathrm{x}$ & postoxidation at T $\geq 473 \mathrm{~K}$ necessary \\
\hline & $\mathrm{ZnO}[34]$ & amorphous & $\mathrm{x}$ & $300-573$ & $\mathrm{TH} / \mathrm{Ta}$ & $\mathrm{ZnO}$ & $10^{-4} \mathrm{O}_{2}$ & stabilization with $\mathrm{SiO}_{2}$ necessary $\left(\right.$ soluble in $\left.\mathrm{H}_{2} \mathrm{O}\right)$ \\
\hline Lanthanide Oxides & $\mathrm{CeO}_{2}[46]$ & single-cryst & $\mathrm{x}$ & 573 & $\mathrm{TH} / \mathrm{W}$ & $\mathrm{CeO}_{2}$ & $10^{-4} \mathrm{O}_{2}$ & \\
\hline Mixed Oxides & $\begin{array}{c}\mathrm{Ga}_{2} \mathrm{O}_{3^{-}} \\
\mathrm{WO}_{3}[41]\end{array}$ & amorphous & dendrites & 573 & $\begin{array}{c}\mathrm{TH} / \mathrm{Ta} \\
(\mathrm{W})\end{array}$ & $\begin{array}{c}\beta-\mathrm{Ga}_{2} \mathrm{O}_{3} ; \\
\mathrm{WO}_{3}\end{array}$ & $\begin{array}{c}10^{-4} \mathrm{O}_{2} \\
\text { Dendrites } \mathrm{Ga}-\text {-enriched }\end{array}$ \\
\hline \\
\hline
\end{tabular}


Samples for structural and spectroscopic characterization

evaporation of $\mathrm{M}_{\mathrm{x}} \mathrm{O}_{\mathrm{y}}$
dissolution of $\mathrm{NaCl}$
in $\mathrm{H}_{2} \mathrm{O}$

Figure 1 

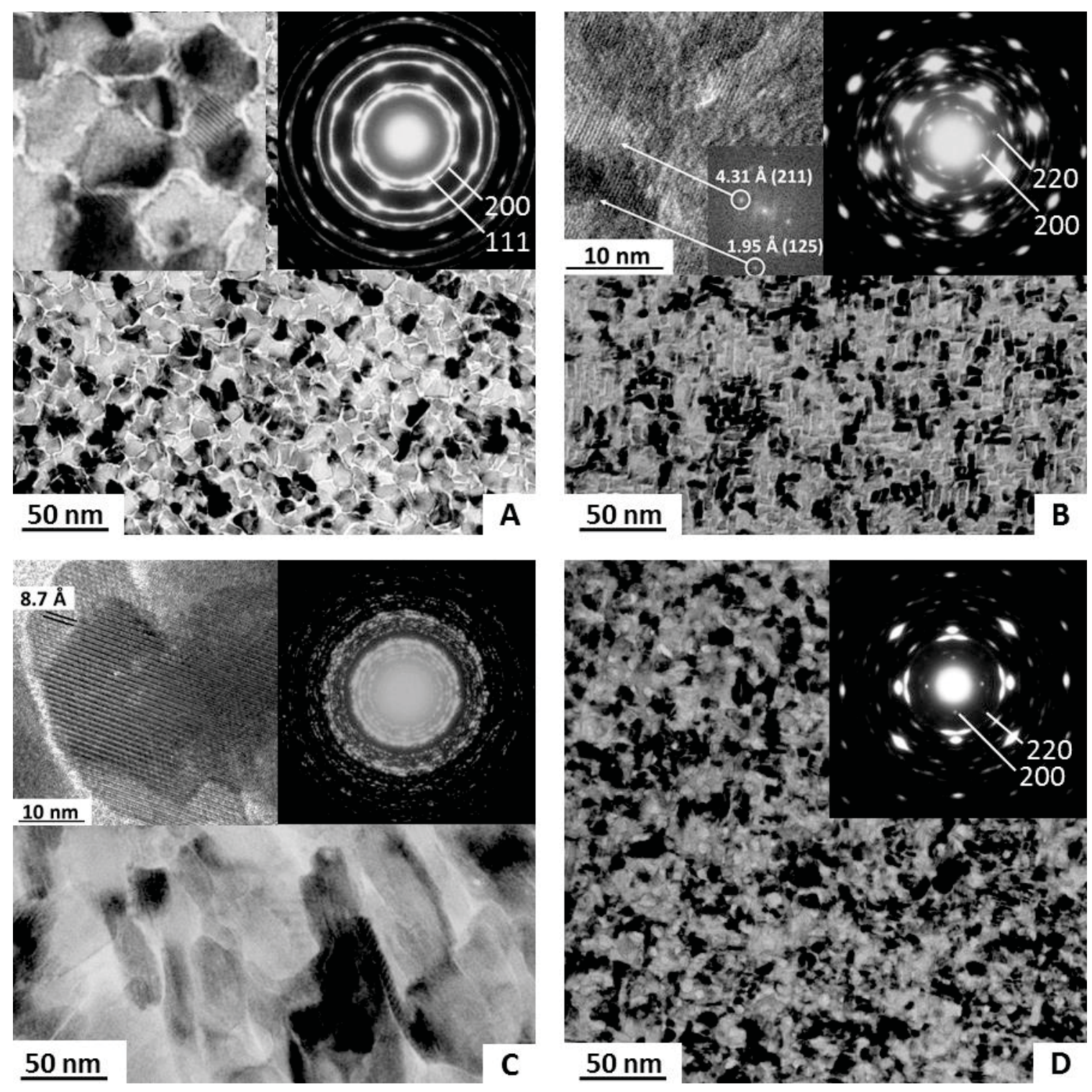

Figure 2 

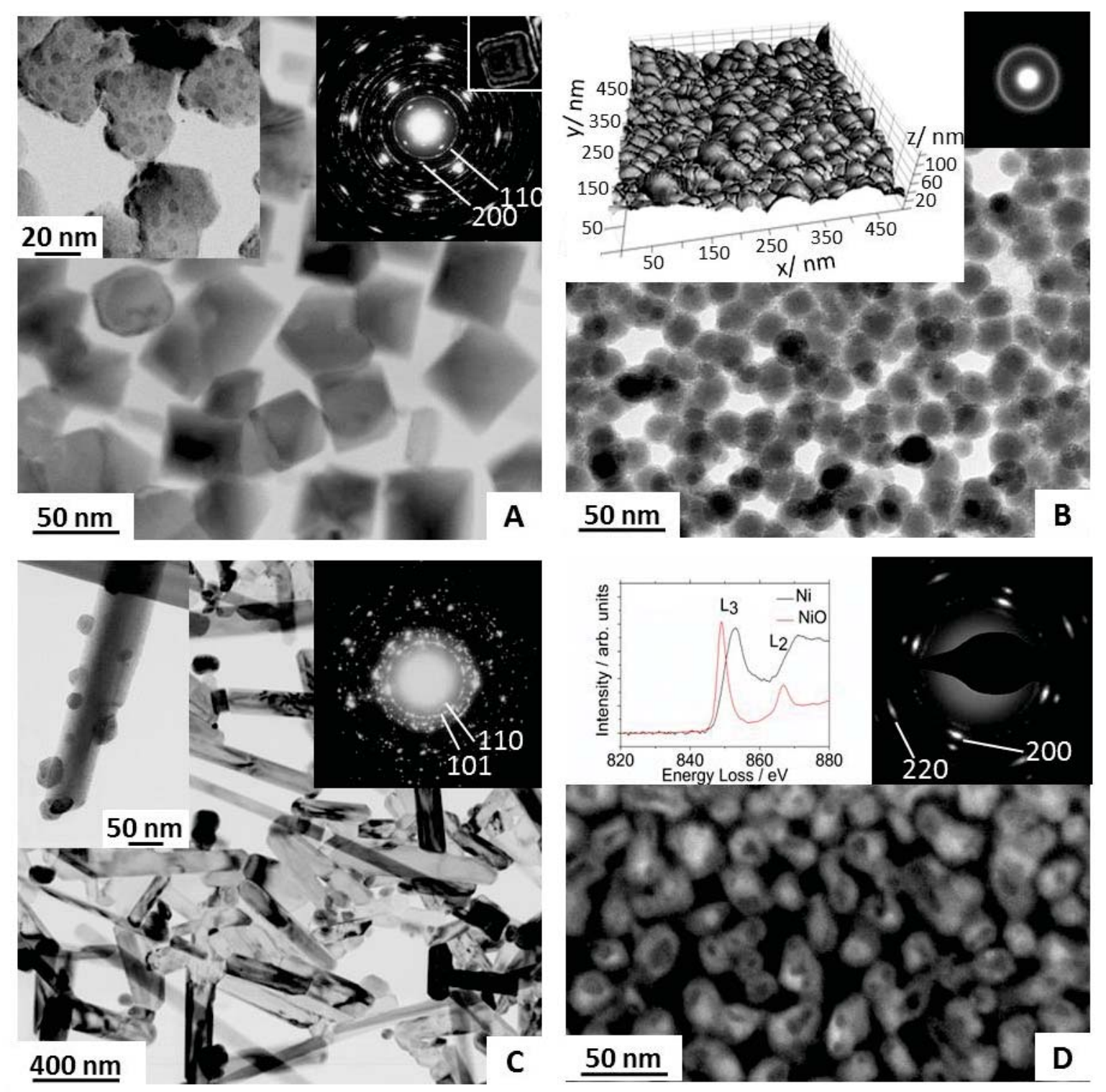

Figure 3 

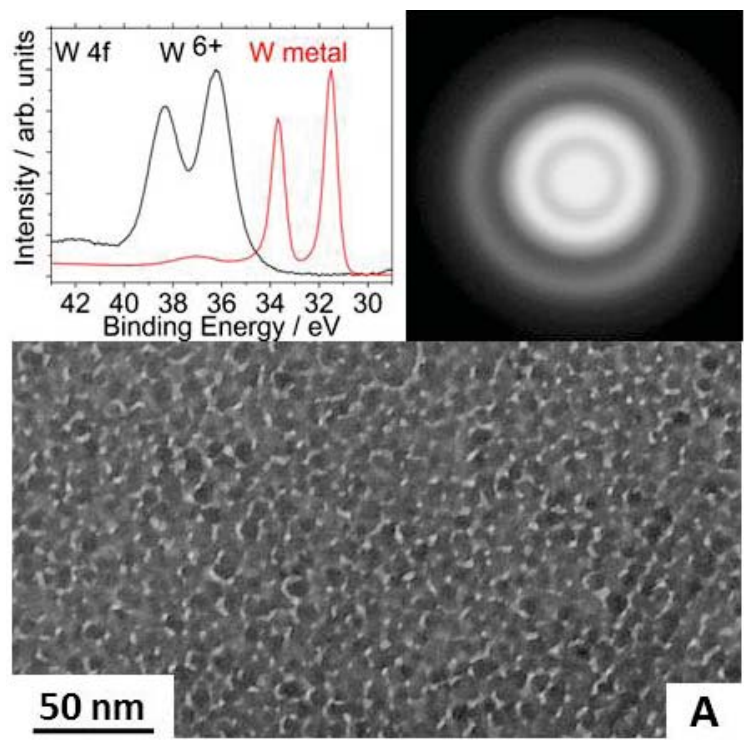

A
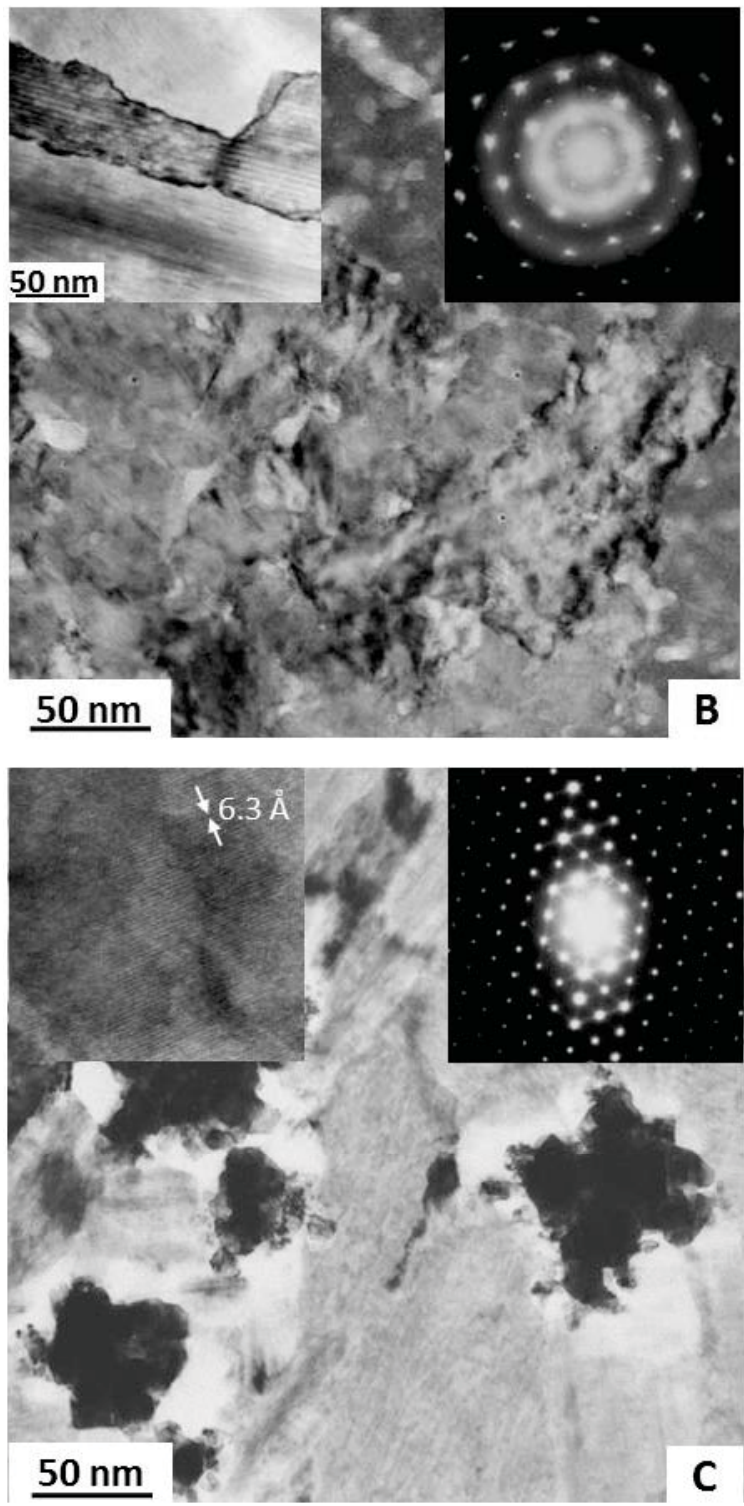

Figure 4
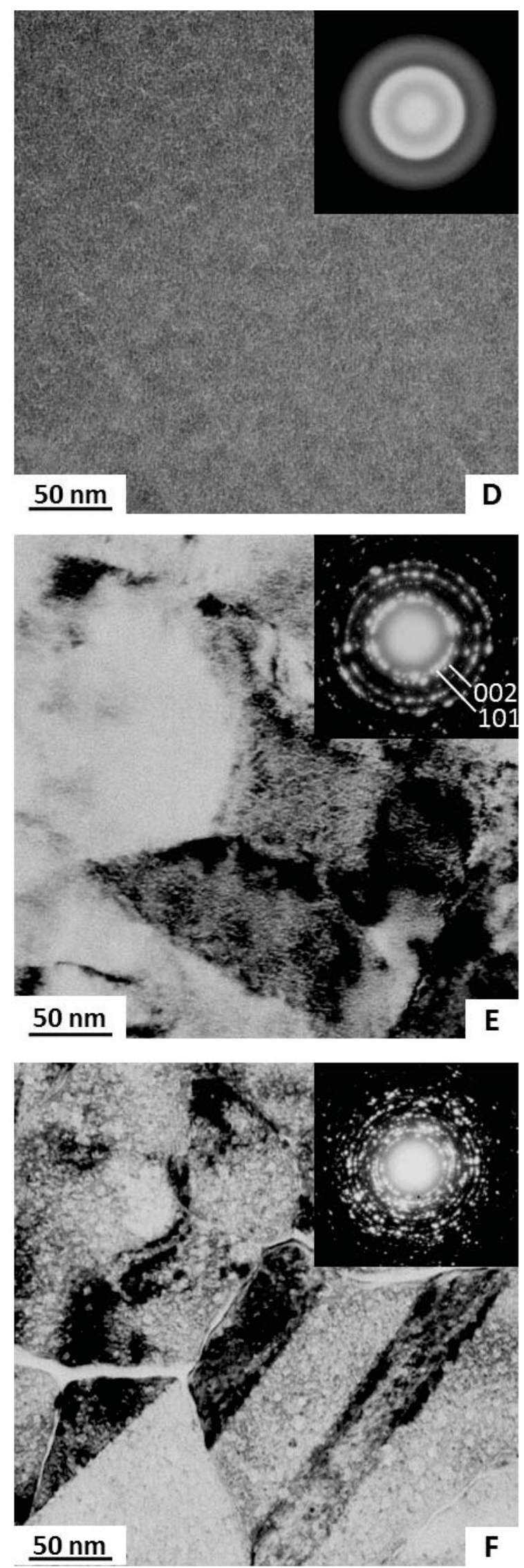

F 


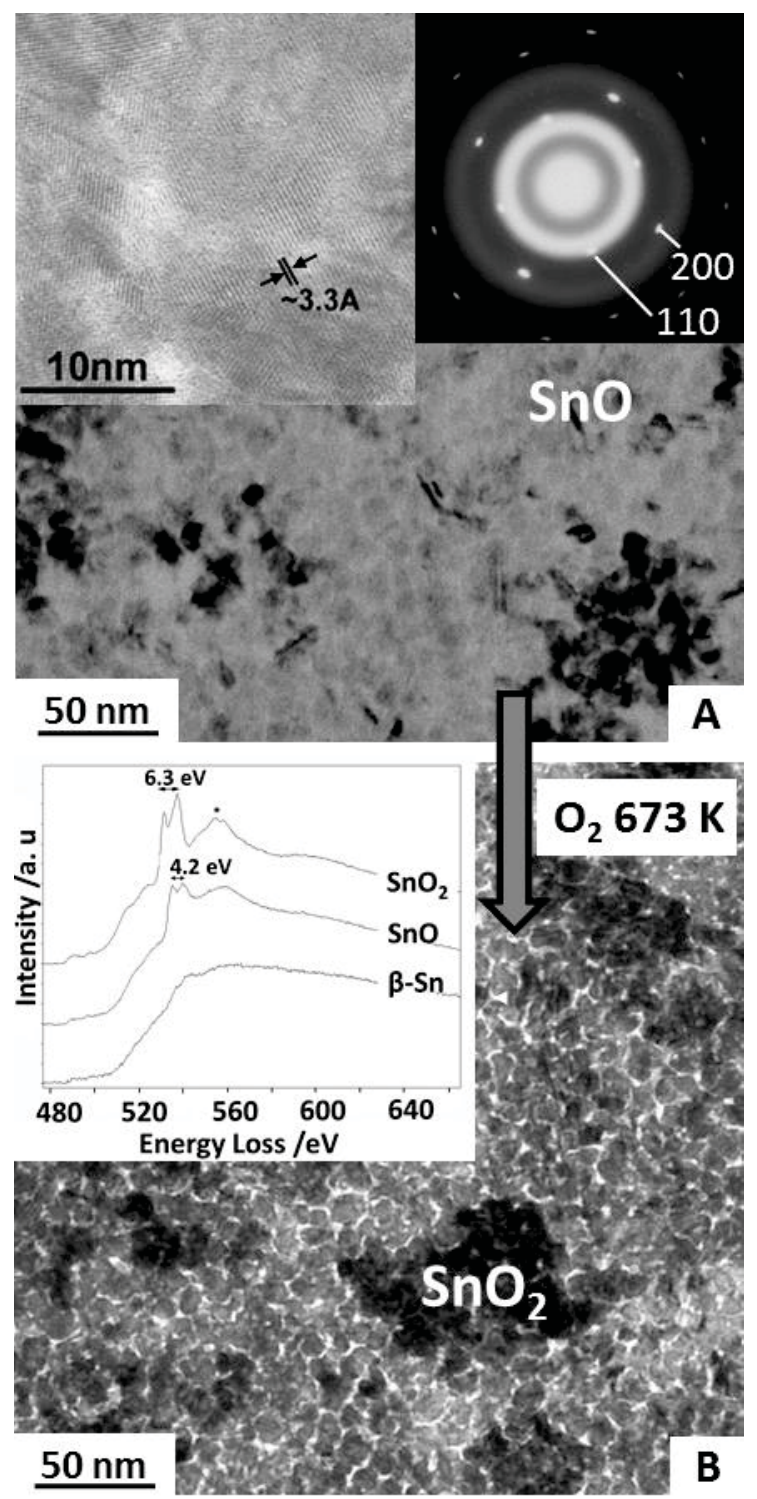

Figure 5 


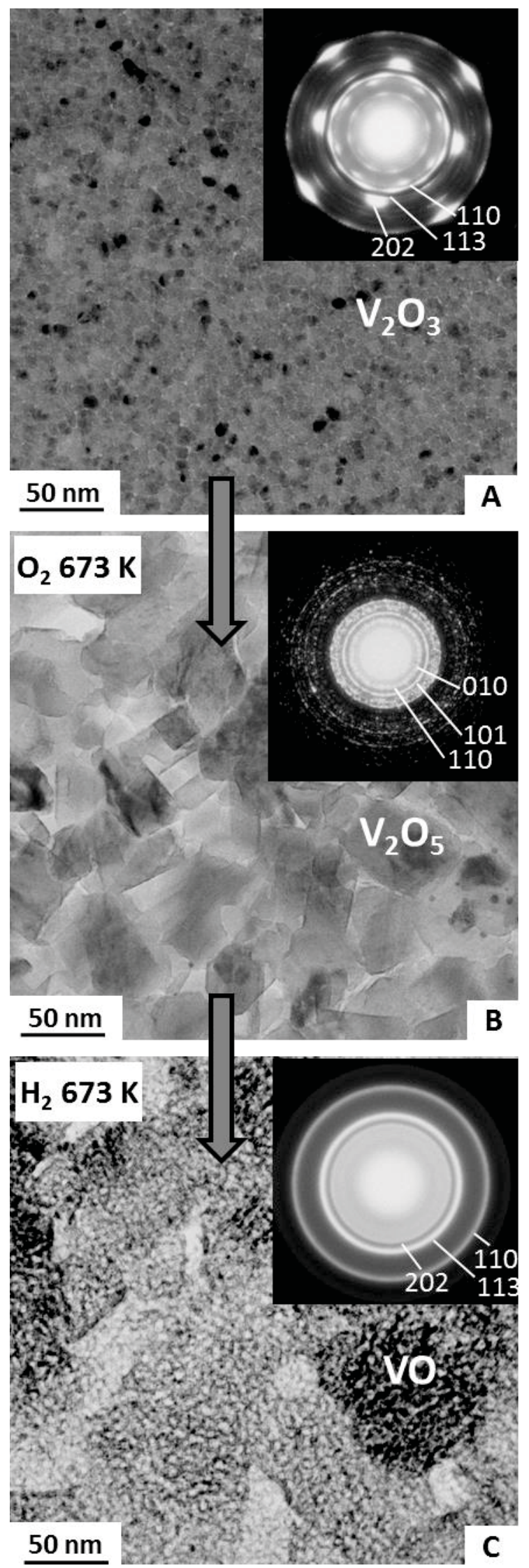

Figure 6 

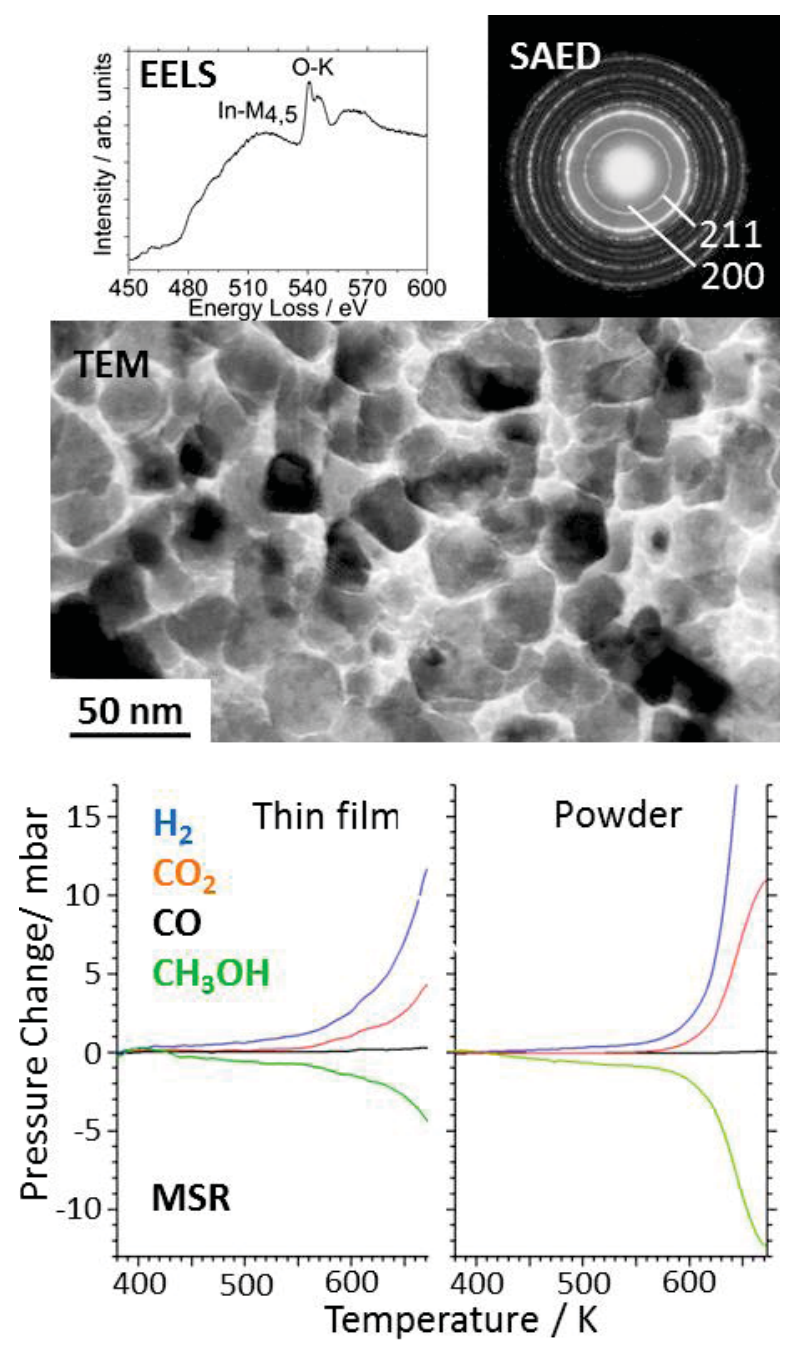

Figure 7 


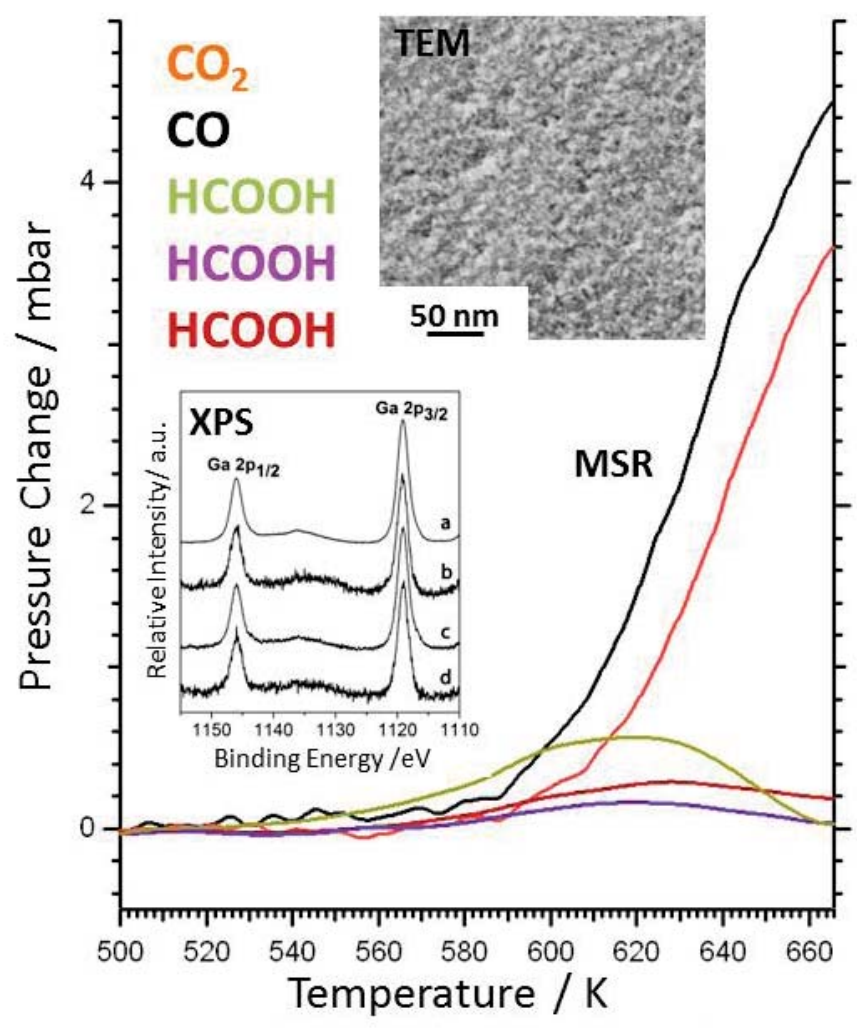

Figure 8 


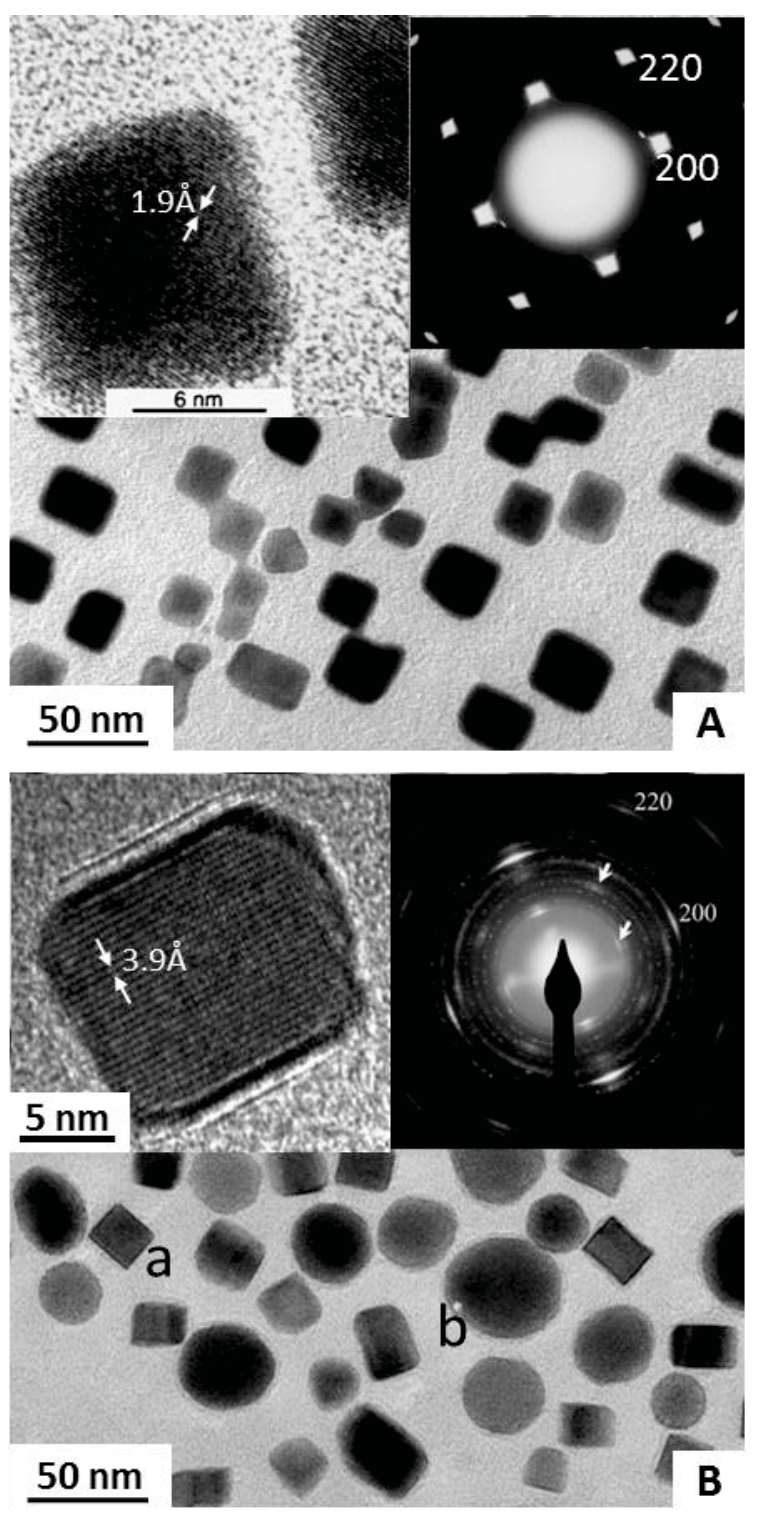

Figure 9 

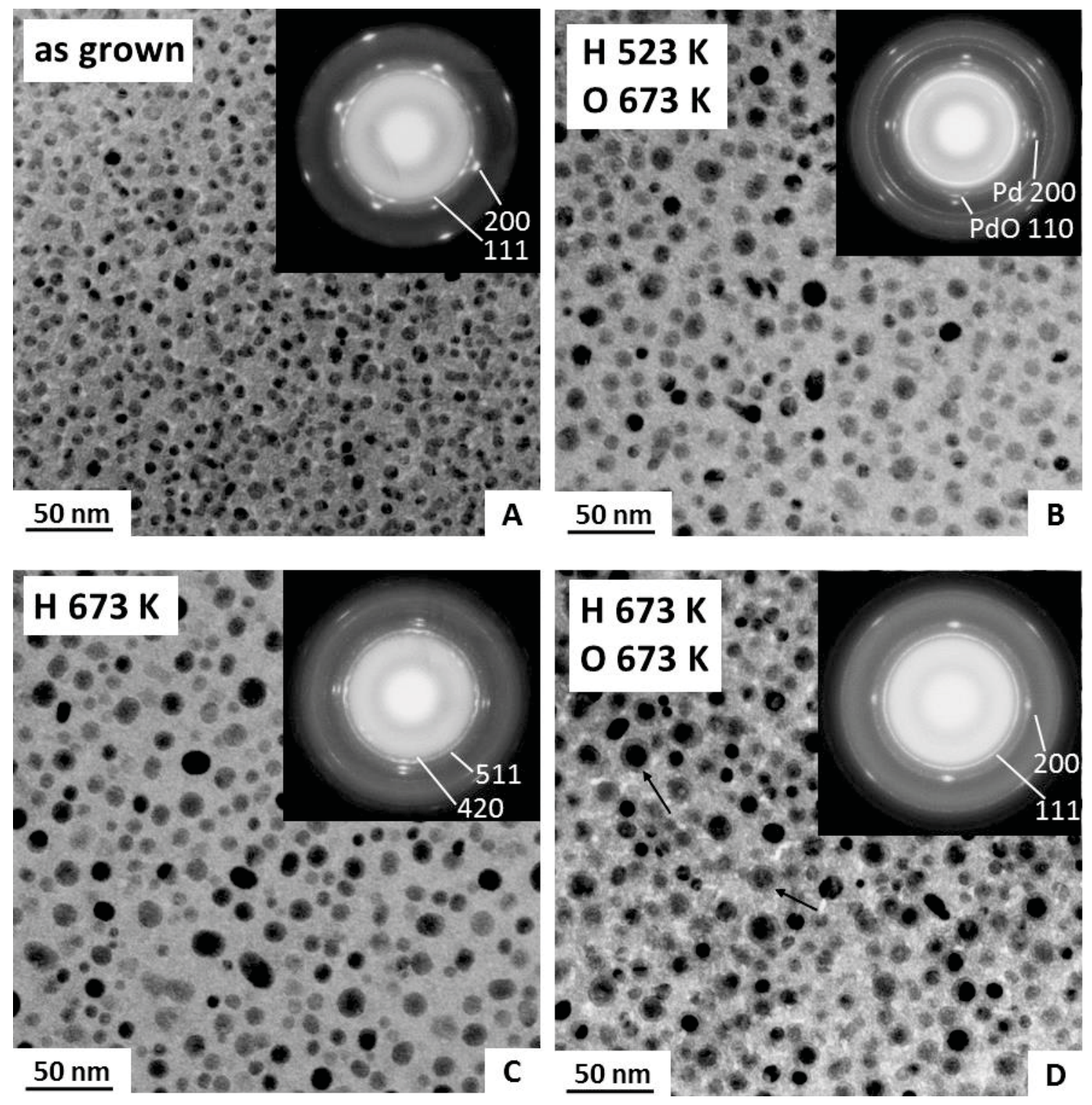

Figure 10 

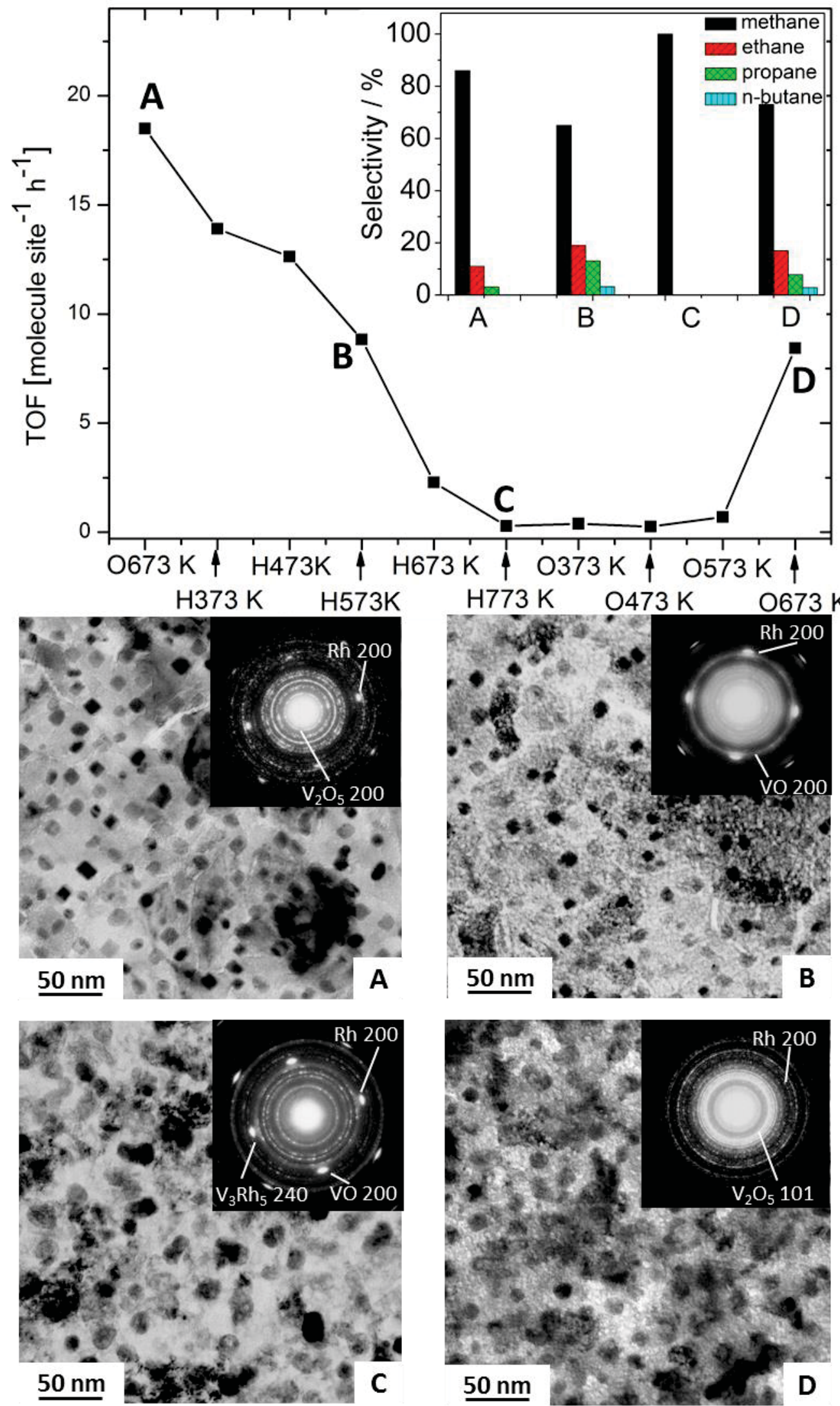

Figure 11 


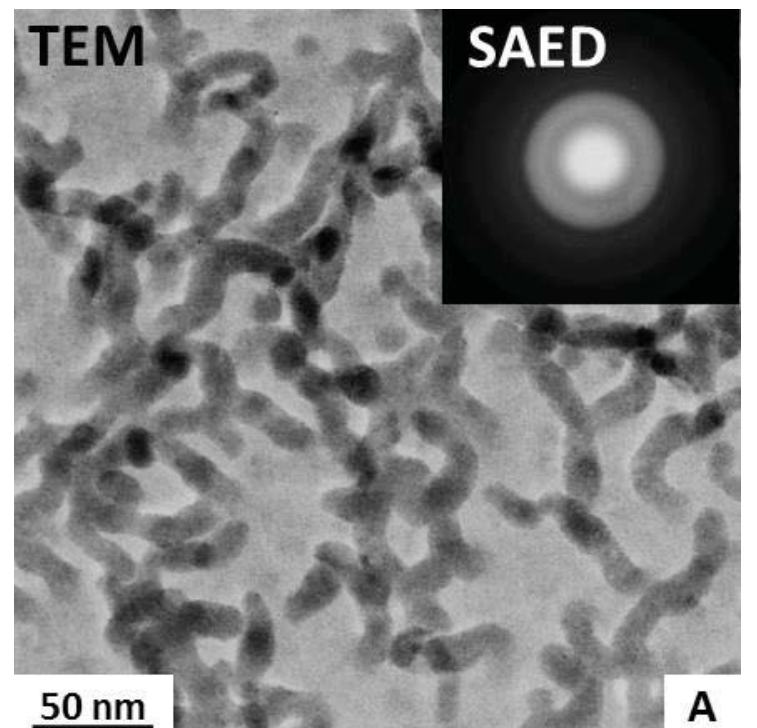

$\underline{50 \mathrm{~nm}}$

A

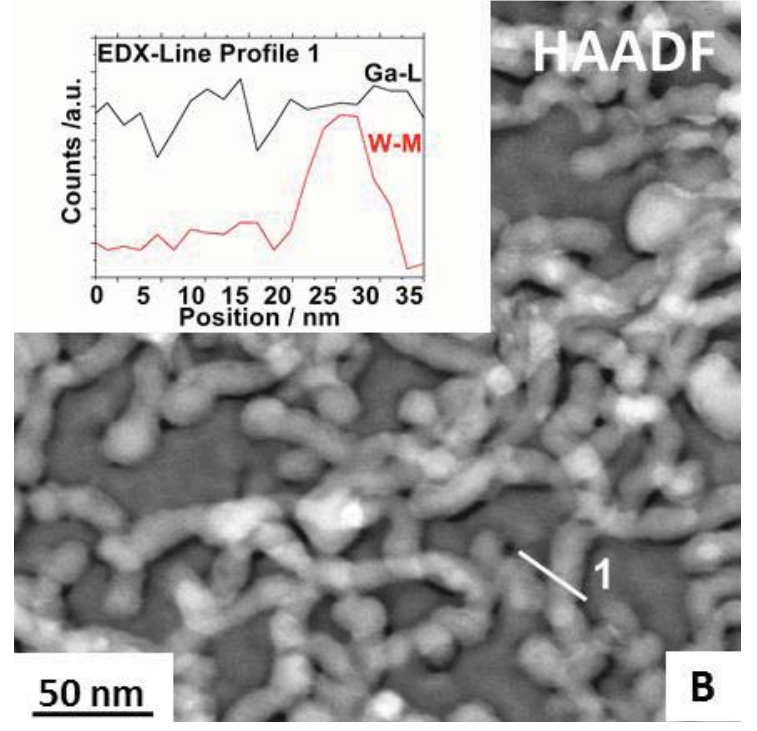

Figure 12 


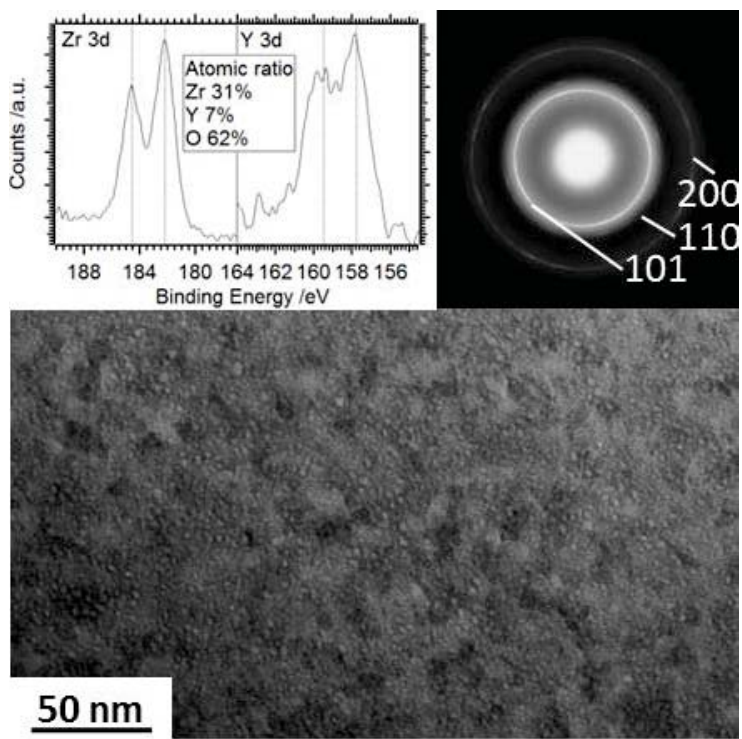

Figure 13 